\begin{tabular}{lr}
\hline \multicolumn{1}{c}{ D Y N A M I C E C O N O M E T R I C } & M O D E L S \\
DOI: http://dx.doi.org/10.12775/DEM.2015.006 & Vol. 15 (2015) 129-156 \\
\hline $\begin{array}{l}\text { Submitted October 22, 2015 } \\
\text { Accepted December 15, 2015 }\end{array}$ & ISSN (online) 2450-7067 \\
\hline
\end{tabular}

\author{
Ewa Ratuszny*
}

\title{
Risk Modeling of Commodities using CAViaR Models, the Encompassing Method and the Combined Forecasts
}

\begin{abstract}
A b s tract. The aim of the research is to compare VaR methods/models for commodities. For risk measurement Conditional Autoregressive Value at Risk models (CAViaR), implied quantile model and encompassing method are used. The aim is to check whether simultaneous use of information both from historical time series and regarding markets' expectation can improve accuracy of forecasts. For this purpose four methods of combining forecasts are used: a simple average combining, an unrestricted linear combination, a weighted averaged combining and a weighted averaged combining using exponential weighting. In the case of the commodities neither the encompassing method nor the combining forecast method improve VaR forecasts. The method of choosing the most adequate model leads to simple CAViaR-SAV model as the source of most optimal measure of risk forecasts. The Kupiec test, the Christoffersen and the Dynamic Quantile test indicate the model as an adequate to forecast $\mathrm{VaR}$ for gold and oil for short positions at the 0.01 and the 0.05 significance level, and for a long position at the 0.05 significance level.
\end{abstract}

K e y w o r d s: CAViaR, VaR, encompassing method, combined forecasts, commodities

J E L Classification: C22, G17.

\section{Introduction}

Value at Risk models should provide an adequate risk forecast both in stability period and in period with high volatility. Accurate assessment of the risk is required for capital management purpose, limit settings and position

\footnotetext{
* Correspondence to: Ewa Ratuszny, Warsaw School of Economics, al. Niepodległości 162, 02-554 Warsaw, Poland, e-mail: ewa.ratuszny@ doktorant.sgh.waw.pl

(C) 2016 Nicolaus Copernicus University Press. All rights reserved. http://www.dem.umk.pl/dem
} 
management. Nowadays there exist many risk measurement methods but none of the models surpasses the others. This paper extends research proposed by Jeon and Taylor (2013) for commodities. Moreover, we apply more complex way to compare VaR methods which helps to avoid overestimation and underestimation of risk.

Value at Risk is defined as the maximum potential loss in portfolio value over a given time period due to adverse market movements (i.e. 500 days), with a given significance level of $\alpha$ (Doman, Doman, 2009; IwaniczDrozdowska, 2005). Engle and Manganelli (2004) have classified the existing VaR methods into three broad categories: parametric, semiparametric and nonparametric. Parametric approach includes RiskMetrics methodology and GARCH models (Piontek, 2000; Fiszeder, 2009; Jajuga, 2011; Mazur, Pipień, 2012), but the weakness of those methods lies in possibility of incorrect specification both of variance model and the error distribution. An interesting parametric method, which becomes increasingly popular, is based on implied volatility. Implied volatility is the expectation of volatility implied by the option market (Chong, 2004; Christoffersen, Mazzotta, 2005; Giot, 2005).

The most common nonparametric approach is the historical simulation, used by about $73 \%$ of banks (Pérignon, Smith, 2010). The main advantage is that the historical $\mathrm{VaR}$ does not require an assumption about parametric form of the distribution of the risk factor returns. Nevertheless the VaR forecast might be inaccurate due to inadequate rolling window of risk factors (Boudoukh et al., 1998). A long data history will typically encompass several regimes with different behavior of market risk factors. Boudoukh et al. (1998), Mittnik and Paolella (2000) and Taylor (2008) propose to apply exponentially weighted approaches to $\mathrm{VaR}$ estimation to overcome those difficulties.

In our research we apply semiparametric approach based on Conditional Autoregressive Value at Risk models (CAViaR). Engle and Manganelli (2004) have proposed models that derive a time-varying VaR directly via autoregression. The models are estimated using robust method, i.e. a nonlinear quantile regression proposed by Koenker and Bassett (1978). The robust approach is widely applied in risk measurement, hedging and portfolio allocation (Taylor, 1999; Umantsev, Chernozhukov, 2001). This approach allows the shape of the conditional returns distributions to vary in time, and for the time-variation to differ for the different quantiles of distribution (Jeon, Taylor, 2013). The autoregressive structure is adequate in case of clustered time series. The previous researches by Ratuszny (2013), 
Ratuszny (2015) indicated that CAViaR models successfuly compete with other VaR methods.

Jeon and Taylor (2013) proposed to combine quantile forecasts elaborated above 25 year ago by Granger (1989) and Granger, White and Kamstra (1989). In their approach the quantile forecasts, obtained from CAViaR models and from method based on implied volatility, are combined. They applied their method not to economic indicators but to risk measurement of position in equity indices such as S\&P500 and DAX30. Moreover, they included in the CAViaR models an additional regressor: a quantiles predictor based on implied volatility (encompassing method).

The authors concluded that linear combining method and arithmetical method generate better forecast over the sample. The observation motivated us to apply their approach to commodities. The Polish researches on combined forecast performed by Grajek (2002), Greszta, Maciejewski (2005), Piłatowska (2009) have also indicated the predominance of combined forecasts over the method based on single approach. In our research we apply CAViaR models, the encompassing method and four combining forecast methods: Simple Average Combining, Unrestricted Linear Combination, Weighted Averaged Combining and Weighted Averaged Combining Optimized using Exponential Weighting. We try to verify the following hypothesis:

The encompassing method or combining forecast methods based on CAViaR models and implied quantile model improve accuracy of VaR for commodities.

The paper is organized as follows. Firstly, we review Value at Risk methodology based on CAViaR models, implied quantile, encompassing method and combining forecast methodology. The part contains also the performance criteria. The second part contains empirical applications of the models. The last part contains concluding remarks.

\section{Review of Value at Risk Methodology}

\subsection{CAViaR Models}

The Conditional Autoregressive Value at Risk model has been introduced by Engle and Manganelli (2004). The basic intuition is to model directly the evolution of the quantile over time, rather than the whole distribution of portfolio returns. The general form of CAViaR models is defined by (Engle, Manganelli, 2004; Doman, Doman, 2009): 
$\operatorname{VaR}_{t}(\alpha, \beta)=f\left(\mathbf{x}_{t}, \boldsymbol{\beta}_{\alpha}\right)=\beta_{0}+\sum_{i=1}^{p} \beta_{i} \operatorname{VaR}_{t-i}(\alpha, \beta)+l\left(\beta_{p+1}, \ldots, \beta_{p+q} \mid \mathrm{F}_{t-1}\right)$,

where $\mathrm{F}_{t-1}$ is the information set available at time $t-1$, and $\boldsymbol{\beta}_{\alpha}=\left(\beta_{0}, \ldots \beta_{p+q}\right)^{\prime}$ is the vector of parameters which is estimated using nonlinear regression quantile techniques. In most practical cases the above formulation is reduced to a first order model:

$$
\operatorname{VaR}_{t}(\alpha, \beta)=\beta_{0}+\beta_{1} \operatorname{VaR}_{t-1}(\alpha, \beta)+l\left(\beta_{2}, y_{t-1}, \operatorname{VaR}_{t-1}(\alpha, \beta)\right),
$$

where $y_{t}=r_{t}-E\left(r_{t} \mid \mathrm{F}_{t-1}\right), r_{t}$ is rate of return, $E\left(r_{t} \mid \mathrm{F}_{t-1}\right)$ is the expected value of rate of returns. The autoregressive term $\beta_{1} \operatorname{VaR}_{t-1}(\alpha, \beta)$ ensures that the $\mathrm{VaR}$ changes smoothly over time. The role of $l\left(\beta_{2}, y_{t-1}, \operatorname{VaR}_{t-1}(\alpha, \beta)\right)$ is the linking the level of explained variable $\operatorname{VaR}_{t}(\alpha)$ to the level of $y$ at the moment $t-1$. That is, it measures the impact of new information in $y$ on the level of VaR. The following CAViaR models are analysed in our research both for long position $(l)$ and short position $(s)$ (Engle, Manganelli, 2004; Doman, Doman, 2009):

1. Symmetric Absolute Value -SAV

$$
\begin{aligned}
& \operatorname{VaR}_{t}^{l}(\alpha, \beta)=\beta_{0}+\beta_{1} \operatorname{VaR}_{t-1}^{l}(\alpha, \beta)+\beta_{2}\left|y_{t-1}\right|, \\
& \operatorname{VaR}_{t}^{s}(\alpha, \beta)=\beta_{0}+\beta_{1} \operatorname{VaR}_{t-1}^{s}(\alpha, \beta)+\beta_{2}\left|y_{t-1}\right| .
\end{aligned}
$$

Current VaR depends on the past value $\operatorname{VaR}_{t-1}$ and absolute value of past rate of return. The model symmetrically responds to both negative and positive past returns.

2. Asymmetric Slope - AS

$$
\begin{aligned}
& \operatorname{VaR}_{t}^{l}(\alpha, \beta)=\operatorname{VaR}_{t-1}^{l}(\alpha, \beta)+\beta_{1} y_{t-1} I\left(y_{t-1} \geq 0\right)+\beta_{3} y_{t-1} I\left(y_{t-1}<0\right), \\
& \operatorname{VaR}_{t}^{s}(\alpha, \beta)=\operatorname{VaR} R_{t-1}^{s}(\alpha, \beta)+\beta_{1} y_{t-1} I\left(y_{t-1} \geq 0\right)+\beta_{3} y_{t-1} I\left(y_{t-1}<0\right),
\end{aligned}
$$

where $I(\cdot)$ is the indicator function. Current $V a R$ depends on its past value $V a R_{t-1}$ and on positive and negative returns that are treated in different way.

3. Indirect GARCH for both short and long position:

$$
\operatorname{VaR}_{t}(\alpha, \beta)=\left[\beta_{1}+\beta_{2} \operatorname{VaR}_{t-1}^{2}(\alpha, \beta)+\beta_{3} y_{t-1}^{2}\right]^{1 / 2} .
$$

Current $\operatorname{VaR}$ is described as GARCH process. The model is correctly specified for rate of returns from $\operatorname{GARCH}(1,1)$ model. 
4. Adaptive - AD

$\operatorname{VaR}_{t}(\alpha, \beta)^{l}=\operatorname{VaR}_{t-1}^{l}(\alpha, \beta)+\beta_{1}\left\{\left[1+\exp \left(G\left[y_{t-1}-\operatorname{VaR}_{t-1}^{l}(\alpha, \beta)\right]\right)\right]^{-1}-\alpha\right\}$

$\operatorname{VaR}_{t}(\alpha, \beta)^{l}=\operatorname{VaR}_{t-1}^{s}(\alpha, \beta)+\beta_{1}\left\{\left[1+\exp \left(G\left[y_{t-1}-\operatorname{VaR}_{t-1}^{s}(\alpha, \beta)\right]\right)\right]^{-1}-\alpha\right\}$,

where $G$ is some positive finite number. If $G \rightarrow \infty$, the second term converges to $\beta\left[I\left(y_{t-1}-\operatorname{VaR}_{t-1}(\alpha, \beta)\right)-\alpha\right]$ for long position and to $\beta\left[I\left(y_{t-1} \geq \operatorname{VaR}_{t-1}(\alpha, \beta)\right)-\alpha\right]$ for short position, where $I(\cdot)$ is the indicator function. In case of a VaR breach the VaR forecast should be increased, otherwise should be slightly decreased. The model aims to reduce the probability of sequences of $\mathrm{VaR}$ breaches and will also make unlikely that the $\mathrm{VaR}$ has never been reached. The disadvantage of this type of CAViaR models is lack of rate of return in explanatory variables set so that the information about extremal market movements is not effectivelly included in model (Doman, Doman, 2009).

Estimation of CAViaR models is performed on the basis of Koenker and Basset (1978) regression quantile methodology, which minimalises the regression quantile objective function of the following form for long $(l)$ and short $(s)$ position, respectively:

$$
\begin{array}{r}
\min _{\beta}\left[\sum_{t \mid y_{t}-\operatorname{VaR}_{t}^{l}(\alpha, \beta)} \alpha\left|y_{t}-\operatorname{VaR}_{t}^{l}(\alpha, \beta)\right|+\right. \\
\left.+\sum_{t y_{t}>-\operatorname{VaR}_{t}^{l}(\alpha, \beta)}(1-\alpha)\left|y_{t}-\operatorname{VaR}_{t}^{l}(\alpha, \beta)\right|\right], \\
\min _{\beta}\left[\sum_{t \mid y_{t} \geq \operatorname{VaR}_{t}^{s}(\alpha, \beta)} \alpha\left|y_{t}-\operatorname{VaR}_{t}^{s}(\alpha, \beta)\right|+\right. \\
\left.\sum_{t \mid y_{t}<\operatorname{VaR}_{t}^{s}(\alpha, \beta)}(1-\alpha)\left|y_{t}-\operatorname{VaR}_{t}^{s}(\alpha, \beta)\right|\right] .
\end{array}
$$




\subsection{Implied Volatility}

Implied volatility reflects market's expectations regarding future volatility. Implied volatility is the key variable in financial investment decision, risk management, derivative pricing, market making, market timing and portfolio selection.

In spite of huge volume of research, no consensus has been reached on usefulness of implied volatility as a predictor for future volatility in comparison with predictions from time series models. There are many empirical studies in which implied volatility overcomes the historical volatility (Szakmary et al. (2003) for futures on equity indices, interest rates, currencies, commodities and crude oil; Pong et al. (2004) for FX; Corredor and Santamaria (2004) for Ibex; Giot and Laurent (2007) for stock indices such as the S\&P100 and S\&P500). Noh and Kim (2006) conclude that both implied volatility and historical volatility using high-frequency returns can outperform each other in forecasting volatility. In their empirical test, historical volatility from high frequency returns performed better in the FTSE100 futures, which tend to be relatively close to normally distributed, while the result of implied volatility was better in the S\&P500 futures, which displays excess skewness even with volatilities from high frequency returns. Implied volatility is also considered as useful variable for estimating quantile of the returns distribution (Giot, 2005; Chong, 2004).

Jeon and Taylor (2013) applied implied volatility to VaR for equity indices S\&P500 and DAX30. They construct an implied quantile ( $I Q$ ) estimator as the product of the implied volatility recorded in the previous period $\sigma_{t-1}^{\text {Implied }}$, and the empirical distribution quantile $Q^{E m p}(\alpha)$ of $\left(y_{t}\right)$ standardised by the implied volatility. The $I Q$ estimator for long and short position is expressed in the following form (Jeon, Taylor, 2013):

$$
\begin{aligned}
& \operatorname{VaR}_{t}^{I Q(l)}(\alpha)=Q^{E m p(l)}(\alpha) \sigma_{t-1}^{\text {Implied }}, \\
& \operatorname{VaR}_{t}^{I Q(s)}(\alpha)=Q^{E m p(s)}(\alpha) \sigma_{t-1}^{\text {Implied }} .
\end{aligned}
$$

The $I Q$ approach captures the market's expectation of future risk. Another advantage is that the method does not assume a particular distribution for the asset returns, and it involves no parameter estimation. Jeon and Taylor (2013) note that this simple approach to capture an 'implied quantile' assumes returns standardised with implied volatility are i.i.d. 


\subsection{Encompassing Method}

Jeon and Taylor (2013) propose to construct one model encompassing competitive forecast models. Such model should generate better forecast than every model separately. This approach is called encompassing (Chong, Hendry, 1986; Diebold, 1989; Grajek, 2002) or plug-in (Jeon, Taylor, 2013). Day and Lewis (1992) in their research show that the implied volatility and models based on historical volatility (EGARCH or GARCH models) does not reflect whole information about volatility. Blair et al. (2001) received completely different results. They shows that implied volatility VIX, is a significant explanatory variable for volatility forecast of S\&P100. Claessen and Mittnik (2002) and Giot (2005) performed research over the sample. Claessen and Mittnik (2002) included the implied volatility VDAX to GARCH model, and show that implied volatility reflect market expectation about future volatility of DAX. Similarly Giot (2005) for Nasdaq and S\&P500 shows that implied volatility VIC and VXN included in GARCH models improves a volatility forecast.

Jeon and Taylor (2013) analyzing the results of previous research of encompassing method, decided to check the possibility to receive a better estimate of $\mathrm{VaR}$ if information from historical time series and information regarding risk expected by market are combined. The rationale for their research was that if the implied volatility forecasts the future well, it should be useful in estimating future quantile of returns distribution. They include the implied quantile expressed by equation (12) or (13) to the CAViaR models as an explanatory variable. The impact of implied volatility on VaR can be determined by coefficient $\beta_{I Q}$.

The following models are analysed in our research (Jeon, Taylor, 2013):

1. Symmetric Absolute Value PlugIn: (SAV-PlugIn):

$$
\begin{aligned}
& \operatorname{VaR}_{t}^{l}(\alpha, \beta)=\beta_{0}+\beta_{1} \operatorname{VaR}_{t-1}^{l}(\alpha, \beta)+\beta_{2}\left|y_{t-1}\right|+\beta_{I Q} \operatorname{VaR}_{t}^{I Q(l)}(\alpha), \\
& \operatorname{VaR}_{t}^{s}(\alpha, \beta)=\beta_{0}+\beta_{1} \operatorname{VaR}_{t-1}^{s}(\alpha, \beta)+\beta_{2}\left|y_{t-1}\right|+\beta_{I Q} \operatorname{VaR}_{t}^{I Q(s)}(\alpha) .
\end{aligned}
$$

2. Asymmetric Slope PlugIn: (AS-PlugIn):

$$
\begin{aligned}
& \operatorname{VaR}_{t}^{l}(\alpha, \beta)=\operatorname{VaR}_{t-1}^{l}(\alpha, \beta)+\beta_{1} y_{t-1} I\left(y_{t-1} \geq 0\right)+\beta_{3} y_{t-1} I\left(y_{t-1}<0\right)+ \\
& +\beta_{I Q} \operatorname{VaR}_{t}^{I Q(l)}(\alpha),
\end{aligned}
$$




$$
\begin{aligned}
& \operatorname{VaR}_{t}^{s}(\alpha, \beta)=\operatorname{VaR}_{t-1}^{s}(\alpha, \beta)+\beta_{1} y_{t-1} I\left(y_{t-1} \geq 0\right)+\beta_{3} y_{t-1} I\left(y_{t-1}<0\right)+ \\
& +\beta_{I Q} \operatorname{VaR}_{t}^{I Q(s)}(\alpha) .
\end{aligned}
$$

3. Indirect GARCH(1,1) PlugIn (IGARCH-PlugIn):

$$
\begin{aligned}
& \operatorname{VaR}_{t}^{l}(\alpha, \beta)=\left\{\beta_{1}+\beta_{2}\left[\operatorname{VaR}_{t-1}^{l}(\alpha, \beta)\right]^{2}+\beta_{3} y_{t-1}^{2}+\beta_{I Q}\left[\operatorname{VaR} R_{t}^{I Q(l)}(\alpha)\right]^{2}\right\}^{1} \\
& \operatorname{VaR}_{t}^{s}(\alpha, \beta)=\left\{\beta_{1}+\beta_{2}\left[\operatorname{VaR}_{t-1}^{s}(\alpha, \beta)\right]^{2}+\beta_{3} y_{t-1}^{2}+\beta_{I Q}\left[\operatorname{VaR}_{t}^{I Q(s)}(\alpha)\right]^{2}\right\}^{\frac{1}{2}} .
\end{aligned}
$$

4. Adaptive PlugIn (AD-PlugIn):

$$
\begin{aligned}
& \operatorname{VaR}_{t}^{l}(\alpha, \beta)^{l}=\beta_{1}+\beta_{2} \operatorname{VaR}_{t-1}^{l}(\alpha, \beta)+ \\
& \beta_{3}\left\{\left[1+\exp \left(G\left[y_{t-1}-\operatorname{VaR}_{t-1}^{l}(\alpha, \beta)\right]\right)\right]^{-1}-\alpha\right\}+\beta_{I Q} \operatorname{VaR}_{t}^{I Q(l)}(\alpha), \\
& \operatorname{VaR}_{t}^{s}(\alpha, \beta)=\beta_{1}+\beta_{2} \operatorname{VaR}_{t-1}^{s}(\alpha, \beta)+ \\
& +\beta_{3}\left\{\left[1+\exp \left(G\left[y_{t-1}-\operatorname{VaR}_{t-1}^{s}(\alpha, \beta)\right]\right)\right]^{-1}-\alpha\right\}+\beta_{I Q} \operatorname{VaR}_{t}^{I Q(s)}(\alpha) .
\end{aligned}
$$

Notations in the models are the same as in part 1.1. and 1.2.1.3.

\subsection{Combining Method to VaR Forecast}

If it is not clear which of two forecasts performs better, a combination can be the best option (Bates, Granger, 1969). Combining methods include information contained in each of individual forecast. According to Armstrong (2001) the combined forecasts should be applied if several different models can be combined to obtain better forecast, there is no certainty about the future state of the object forecast, and where large forecasting error involves a high cost. By combining forecasters should able to reduce inconsistency in estimates and to cancel out biases to some extent.

The work by Bates and Granger (1969) often is considered to be the seminal article on combining forecasts. They combined two separate sets of forecasts of airline passenger data to form a composite set of forecasts. They concluded that the composite set of forecasts can yield lower mean-square error than either of the original forecasts. Past errors of each of the original forecasts are used to determine the weights to attach to these two original forecasts in forming the combined forecasts. They also examined different methods of deriving these weights. Combined forecasts for economy 
indicators are subject of research of Crane and Crotty (1967), Zarnowitz (1967), Nelson $(1972,1984)$.

Despite the criticism of combined forecasts (e.g. Diebold (1989) showed that it is better to improve one of the single models, rather than relying on combining methods of forecast derived from models with incorrect specifications), this approach has become the subject of further research.

Combining forecasts for the variation is subject of research of Doidge and Wei (1998), Armendola and Storti (2008), Donaldson and Kamstra (2005).

There are very few studies about combining quantile forecasts. Granger (1989) and Granger et al. (1989) introduce the idea of using quantile regression to combine quantile forecasts. Taylor and Bunn (1998) assess the usefulness of different restrictions on the parameters of the quantile regression combination. Giacomini and Komunjer (2005) describe how encompassing tests can be performed for two quantile predictors using the quantile regression combining framework. They apply their proposal to VaR estimates of the S\&P500 based on two time series volatility forecasting methods.

Jeon and Taylor (2013) in their research applied the following four combined mehods: Simple Average Combining (SimpAvg), Unrestricted Linear Combination (LinearComb), Weighted Averaged Combining (WtdAvg) and Weighted Averaged Combining Optimized using Exponential Weighting (WtdAvgExp).

\section{Simple Average Combining (SimpAvg)}

The simplest and most widely used forecast combining method is to take the simple arithmetic mean of the individual forecasts. We consider the simple average of the quantile forecasts from the IQ method and one CAViaR model, as in expression (3-9) (Jeon and Taylor, 2013):

$$
\begin{aligned}
& \operatorname{VaR}_{t}^{l}(\alpha)=\frac{1}{2} Q_{t}^{I Q(l)}(\alpha)+\frac{1}{2} \operatorname{VaR}_{t}^{\operatorname{CAV} \operatorname{Via}(l)}(\alpha, \beta), \\
& \operatorname{VaR}_{t}^{s}(\alpha)=\frac{1}{2} Q_{t}^{I Q(s)}(\alpha)+\frac{1}{2} \operatorname{VaR}_{t}^{\operatorname{CAViaR}(s)}(\alpha, \beta) .
\end{aligned}
$$

The method will be here denoted as SimpAvg according to Jeon and Taylor (2013) nomenclature. The aim of this approach is to determine the combination of forecasts with lower error variance than in case of individual forecasts. 


\section{Unrestricted Linear Combination (LinearComb)}

A traditional approach to combining is to compute linear combinations of forecasts, called also regression method (Jeon and Taylor, 2013). The method will be dnoted as LinearCom according to Jeon and Taylor (2013) nomenclature. Forecast is formed on the basis of an IQ forecast and one of CAViaR models (Jeon and Taylor, 2013):

$$
\begin{aligned}
& \operatorname{VaR}_{t}^{l}(\alpha)=\gamma_{1}+\gamma_{2} Q_{t}^{I Q(l)}(\alpha)+\gamma_{3} \operatorname{VaR}_{t}^{\operatorname{CAV} \operatorname{Via}(l)}(\alpha, \beta), \\
& \operatorname{VaR}_{t}^{s}(\alpha)=\gamma_{1}+\gamma_{2} Q_{t}^{I Q(s)}(\alpha)+\gamma_{3} \operatorname{VaR}_{t}^{\operatorname{CAViaR}(s)}(\alpha, \beta) .
\end{aligned}
$$

The parameters $\gamma_{2}$ and $\gamma_{3}$ inform about the dynamics of forecasted variable. If the sum of the parameters $\gamma_{2}$ and $\gamma_{3}$ is less than unity, the individual predictions are more volatile than the risk measure VaR. If the sum of the parameters is greater than one, then the individual forecasts are of less dynamic than VaR.

There are several difficulties with the combination method. The first is related to collinearity of individual forecasts. If the individual predictions are quite good, they would not differ significantly and this entails the phenomenon of collinearity. Consequently, the low-significance and high randomness of estimated weights are obtained. Another issue is the autocorrelation of the random component, caused by autocorrelation of dependent variable. In order to solve this problem Diebold (1988) proposed to estimate the ARCH model. The third issue is related with the inability to impose zero restrictions for correlation between the errors of individual forecasts, when examining the behavior of individual forecasts in the past. In addition, regression method requires a large data sets, which in case of time series is fullfilled. The advantage of this method is the lack of restrictions on the parameters and lack of assumptions about unbiasedness of individual forecasts.

\section{Weighted Averaged Combining (WtdAvg)}

The Weighted Averaged Combining method is based on the relation between forecast error in the past. In this approach the unbiasedness of quantile forecast is assumed (Granger (1989)). Error variance of combined forecast will be equal or smaller than of the individual forecasts. The method in our research will be noted as WtdAvg according to Jeon and Taylor (2013) nomenclature. The resultant quantile forecast is of the form (26-27), without 
constant, where combining weights are constrained to be between zero and one.

$$
\begin{aligned}
& \operatorname{VaR}_{t}^{l}(\alpha, \omega)=\omega Q_{t}^{I Q(l)}(\alpha)+(1-\omega) \operatorname{VaR}_{t}^{\operatorname{CAV} \operatorname{Via}(l)}(\alpha, \beta), \\
& \operatorname{VaR}_{t}^{s}(\alpha, \omega)=\omega Q_{t}^{I Q(s)}(\alpha)+(1-\omega) \operatorname{VaR}_{t}^{\operatorname{CAV} \operatorname{Via}(s)}(\alpha, \beta) .
\end{aligned}
$$

Clemen (1986) advocates the use of the weighted average even if the forecasts are biased, arguing that gains in efficiency can be made at the cost of some bias. Bunn (1989) noted greater robustness of the method compared with regression method. Taylor and Bunn (1998) pointed out that the value of the weight indicates the relative explanatory powers of the two quantile predictors.

\section{Weighted Averaged Combining Optimized using Exponential Weighting (WtdAvgExp).}

The method is similar to Weighted Averaged Combining but additionally the Exponential Weighting factor for the optimisation of the combining weight is applied. The factor gives greater weight to the more recent observations in the quantile regression optimisation (Taylor (2008)). In this way the nonstationarity problem of weights is solved. This is particularly important when the time series exhibits time-varing and cyclical volatility. Boudoukh et al. (1998) insist that such an approach is a reasonable compromise between statistical precision and adaptation to the latest information. Exponentially Weighted Quantile Regression (EWQR) method solves the following minimizing problem (Jeon, Taylor, 2013):

$$
\begin{gathered}
\min _{\omega}\left(\sum_{t \mid y_{t} \leq-\operatorname{VaR} t_{t}^{l}(\alpha, \omega)} \lambda^{T-t} \alpha\left|y_{t}-\operatorname{VaR}_{t}^{l}(\alpha, \omega)\right|+\right. \\
\left.+\sum_{t \mid y_{t}>-\operatorname{VaR}_{t}^{l}(\alpha, \omega)} \lambda^{T-t}(1-\alpha)\left|y_{t}-\operatorname{VaR}_{t}^{l}(\alpha, \omega)\right|\right) \\
\min _{\omega}\left(\sum_{t \mid y_{t} \geq V a R_{t}^{s}(\alpha, \omega)} \lambda^{T-t} \alpha\left|y_{t}-\operatorname{VaR}_{t}^{s}(\alpha, \omega)\right|+\right. \\
\left.+\sum_{t \mid y_{t}<\operatorname{VaR}_{t}^{s}(\alpha, \omega)} \lambda^{T-t}(1-\alpha)\left|y_{t}-\operatorname{VaR}_{t}^{s}(\alpha, \omega)\right|\right)
\end{gathered}
$$


where $\operatorname{VaR}_{t}^{l}(\alpha)$ and $\operatorname{VaR}_{t}^{s}(\alpha)$ are expressed in equations (26)-(27). A lower value of the decay parameter $\lambda$ implies faster exponential decay, and hence more weight is given to the recent observations and less historical information is captured. This method is noted as WtdAvgExp according to Jeon and Taylor (2013).

\subsection{Out-of-sample diagnostics}

Regulators can apply backtest for evaluating the accuracy of the VaR models, but this method misclassifies forecasts from inaccurate models as acceptably accurate. In our research the out-of-sample diagnostic of $\mathrm{VaR}$ is performed on the basis tests and measures, i.e. backtests, tests based on Bernoulli trials model, the Dynamic Quantile test, regulatory loss, binary loss, firm's loss.

The LR Test of Unconditional Coverage (Kupiec test) evaluates the model, taking into account both too much and too few exceedances. Its disadvantage, however, is that it does not take into account the distribution of exceedances in the sample. A well-functioning VaR model should be characterized by the absence of autocorrelation in the indicator function what can be done by performing the Dynamic Quantile test. The model is considered adequate if the number of exceedances corresponds to the assumptions and there is no autocorrelation. In case of no exceedances we consider that the model is inadequate, because of overestimation of VaR. Recall the construction and interpretation of these tests/measures.

Kupiec (1995), Christoffersen (1998), Rachev and Mittnik (2002) proposed the indicator variable $\left(\xi_{t}\right)$ for time $\mathrm{t}$, made at time $t-1$, which is defined as:

$$
\begin{aligned}
\xi_{t}^{l} & =\left\{\begin{array}{llc}
0 & \text { if } & y_{t+n} \geq-\operatorname{VaR}_{t}^{l}(\alpha) \\
1 & \text { if } & y_{t+n}<-\operatorname{VaR}_{t}^{l}(\alpha)
\end{array},\right. \\
\xi_{t}^{s} & =\left\{\begin{array}{llc}
0 & \text { if } & y_{t+n} \\
1 & \text { if } & y_{t+n}>\operatorname{VaR}_{t}^{s}(\alpha)
\end{array}\right.
\end{aligned} .
$$

On basis of the variable we perform backtesting. In the backtest we check ex post if observed loss $\left(y_{t+n}\right)$ breaches the forecast $\mathrm{VaR}$ at the time $t$. If the $\mathrm{VaR}$ is indicated on the significance level of $\alpha$, an appriopriate model should also indicate fraction of exceedances of the realised loss at the level of $\alpha$. If the fraction of breaches is much greater than assumed, it means that 
the model underestimates the size of VaR. Lower number of exceedances means in turn that the model overestimates the Value at Risk (Doman, Doman, 2009).

Kupiec (1995) proposes to treat $\xi_{t}^{p o z}: t=T, T+1, \ldots, T+T^{\prime}$, where $p o z$ denotes instrument position, i.e. $l$ - long or $s$ - short, as sequence of Bernoulli trials of independent variables with the same probability of success:

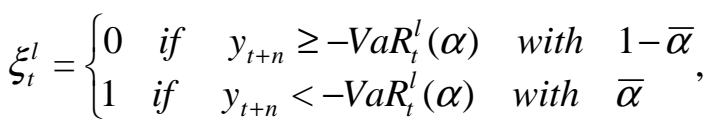

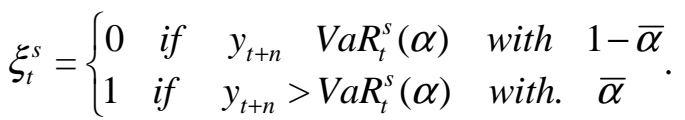

The null hipotesis of Kupiec test is: $H_{0}: \bar{\alpha}=\alpha$.

The likelihood ratio test statistic $L R_{u c}$ (ang. the LR Test of Unconditional Coverage) is given by an equation (Pipień, 2006):

$$
L R_{u c}=2\left\lfloor\ln \left\{(1-\bar{\alpha})^{T^{\prime}-1-S} \hat{\alpha}^{S}\right\}-\ln \left\{(1-\alpha)^{T^{\prime}+1-S} \alpha^{S}\right\}\right) \text {, }
$$

where $S=\sum_{t=T}^{T+T^{\prime}} \xi_{t}^{p o z}$ means the total number of exceedances and $\hat{\alpha}=\frac{1}{T^{\prime}+1} \sum_{t=T}^{T+T^{\prime}} \xi_{t}^{p o z}$ is the assessment of the likelihood of success. With a true null hypothesis, test statistic has asymptotic distribution $\chi_{1}^{2}$. The null hypothesis is rejected if the statistical value is above a critical value, i.e. $L R_{u c}>3.84$.

Christoffersen (1998) combines the above tests for unconditional coverage and independence. In effect, the null hypothesis of the unconditional coverage test will be tested against the alternative of the independence test. The statistics of the Joint Test of Coverage and Independence is expressed by the following equation (Christoffersen, 1998):

$$
L R_{c c}=L R_{u c}+L R_{\text {ind }} \text {. }
$$

where:

$$
\begin{aligned}
& L R_{\text {ind }}=2\left[\ln \left\{\left(1-\hat{\pi}_{01}\right)^{T_{00}} \hat{\pi}_{01}^{T_{01}}\left(1-\hat{\pi}_{11}\right)^{T_{10}} \hat{\pi}_{11}^{T_{11}}\right\}-\right. \\
& \left.-\ln \left\{\left(1-\hat{\pi}_{2}\right)^{\left(T_{00}+T_{10}\right)} \hat{\pi}_{2}^{\left(T_{01}+T_{11}\right)}\right\}\right]
\end{aligned}
$$


where $\hat{\pi}_{i j}=T_{i j} /\left(T_{i 0}+T_{i 1}\right) ; \hat{\pi}=\left(T_{01}+T_{11}\right) / T$ for $j, i=0,1, T_{i j}$ - number of points at time $\{t ; 2 \leq t \leq T\}$ for which the $I_{t}=i$ follows $I_{t+1}=j$.

The test statistic has asymptotic distribution $\chi_{2}^{2}$. The null hypothesis is rejected if the statistical value is above a critical value, i.e. $L R_{c c}>5.99$.

The Dynamic Quantile test was constructed to check the absence of autocorrelation in sequence $\left\{\xi_{t}^{p o z}: t=T, T+1, \ldots, T+T^{\prime}\right\}$, where $\xi_{t}^{\text {poz }}$ is binary variable expressed by equations (30)-(31). Define for long position $\operatorname{Hit}_{t}^{l}(\alpha)=I\left(y_{t}<-\operatorname{VaR}_{t}(\alpha)\right)-\alpha$ and for short position: $\operatorname{Hit}_{t}^{s}(\alpha)=I\left(y_{t}>\operatorname{VaR}_{t}(\alpha)\right)-(\alpha)$, where $I(\cdot)$ is indication function. The Dynamic Quantile test verifies two hypothesis simultaneously:

- $H_{01}: E\left(H i t_{t}^{p o z}(\alpha)\right)=0$,

- $H_{02}$ : variable $\mathrm{Hit}_{t}^{p o z}(\alpha)$ is uncorrelated with the variables included into information set.

Engle and Manganelli (2004) jointly verify the above hypothesis by the regression of the following form:

$$
\operatorname{Hit}^{p o z}(\alpha)=\lambda \mathbf{X}+\varepsilon_{t},
$$

where $\mathbf{X}$ is the matrix $X=\left[x_{t, j}\right]$ of dimension $T \times k$, where in the first column are the ones, then $p$ columns contains variables Hit $_{t-1}, \ldots$ Hit $_{t-p}$, and $k-p-1$ remaining columns - an additional independent variables (including $\left.V a R_{t}\right) c T h e$ Dynamic Quantile test statistic is expressed by the equation:

$$
\frac{\hat{\lambda}^{\prime} \mathbf{X}^{\prime} \mathbf{X} \hat{\lambda}}{\alpha(1-\alpha)}
$$

where $\hat{\lambda}=\left(X^{\prime} X\right)^{-1} X^{\prime} Y$ is the OLS estimate of parameters $\lambda$. The test statistic is asymptotically distributed $\chi_{k}^{2}$.

Detailed test results are available from the author on the request. In table (12)-(13) bolded value indicate models which are adequate under assumed criterion.

Lopez (1998) proposed the loss functions evaluation method not based on hypothesis testing framework, but rather on assigning to the $\mathrm{VaR}$ estimates a numerical score that reflects specific regulatory or firm's 
concern. In our research we take into account binary loss, regulatory loss and firm's loss.

Let loss function will be implied by the binomial method which takes value 0 or 1 related with observed VaR breach:

$$
\begin{aligned}
& f_{t}^{l}\left(y_{t+n}, \operatorname{VaR}_{t}^{l}(\alpha)\right)=\left\{\begin{array}{lll}
0 & \text { for } & y_{t+n} \geq-\operatorname{VaR}_{t}^{l}(\alpha) \\
1 & \text { for } & y_{t+n}<-\operatorname{VaR}_{t}^{l}(\alpha)
\end{array},\right. \\
& f_{t}^{s}\left(y_{t+n}, \operatorname{VaR}_{t}^{s}(\alpha)\right)=\left\{\begin{array}{lll}
0 & \text { for } & y_{t+n}<\operatorname{VaR}_{t}^{s}(\alpha) \\
1 & \text { for } & y_{t+n} \geq \operatorname{VaR} R_{t}^{s}(\alpha)
\end{array}\right.
\end{aligned}
$$

Binary loss (BL) is described by the number of exceptions observed in period from $t=T+n$ to $t=T+T^{\prime}+n$ (Lopez, 1998; Pipien, 2006):

$$
B L^{p o z}=\sum_{t=T}^{T+T^{\prime}} f_{t}^{p o z} .
$$

The smaller is the number of exceedances, the better rating for the models will be assigned. This criterion favors models which overestimate the VaR and assign low score for the models that generate liberal VaR forecasts. In the assessment of $\mathrm{VaR}$ forecasts an important issue is to take into account the size of the losses that are associated with exceptions of VaR by observation $y_{t+n}$. Function (41) includes only the fact of exceptions, and does not take into account the size of the losses arising from an extremal market movement.

The second loss function proposed by Lopez (1999) contains both the magnitude and the number of exceptions:

$$
\begin{aligned}
& f_{t}^{l}\left(y_{t+n}, \operatorname{VaR}_{t}^{l}(\alpha)\right)=\left\{\begin{array}{lll}
0 & \text { for } & y_{t+n} \geq-\operatorname{VaR} R_{t}^{l}(\alpha) \\
1+\left(y_{t+n}+\operatorname{VaR}_{t}^{l}(\alpha)\right)^{2} & \text { for } & y_{t+n}<-\operatorname{VaR}_{t}^{l}(\alpha)
\end{array},\right. \\
& f_{t}^{s}\left(y_{t+n}, \operatorname{VaR}_{t}^{s}(\alpha)\right)=\left\{\begin{array}{lll}
0 & \text { for } & y_{t+n}<\operatorname{VaR} R_{t}^{s}(\alpha) \\
1+\left(y_{t+n}-\operatorname{VaR}_{t}^{s}(\alpha)\right)^{2} & \text { for } & y_{t+n} \geq \operatorname{VaR}_{t}^{s}(\alpha)
\end{array}\right.
\end{aligned}
$$

Regulatory loss (RL) is expressed as follows (Sarma et al., 2003):

$$
R L^{p o z}=\sum_{t=T}^{T+T^{\prime}} f_{t}^{p o z}
$$

Thus, as before, a score of one is imposed when an exception occurs, but also, an additional term based on its magnitude is included. The numerical score increases with magnitude of the exception and can provide additional 
information on how the underlying VaR model forecasts the lower tail of the inderlying distribution.

Sarma et al. (2003) pointed out that in financial institutions exists conflict between profit maximization and the duty of protection against market risk. The duty is related with Basel III which imposes an obligation to maintain the capital requirements to cover potential losses. Sarma et al. (2003) propose to incorporate in the loss function the additional costs arising from the capital adequacy. The loss function is:

$$
\begin{aligned}
& f_{t}^{l}\left(y_{t+n}, \operatorname{VaR}_{t}^{l}(\alpha)\right)=\left\{\begin{array}{l}
c V a R_{t}^{l}(\alpha) \text { for } \quad y_{t+n} \geq-\operatorname{VaR}_{t}^{l}(\alpha) \\
1+\left(y_{t+n}+\operatorname{VaR}_{t}^{l}(\alpha)\right)^{2} \quad \text { for } \quad y_{t+n}<-\operatorname{VaR}_{t}^{l}(\alpha)
\end{array}\right. \\
& f_{t}^{s}\left(y_{t+n}, \operatorname{VaR}_{t}^{s}(\alpha)\right)=\left\{\begin{array}{l}
c \operatorname{VaR}_{t}^{s}(\alpha) \text { for } \quad y_{t+n}<\operatorname{VaR}_{t}^{s}(\alpha) \\
1+\left(y_{t+n}-\operatorname{VaR}_{t}^{s}(\alpha)\right)^{2} \text { for } y_{t+n} \geq \operatorname{VaR} R_{t}^{s}(\alpha)
\end{array}\right.
\end{aligned}
$$

where the parameter $c>0$ specifies the opportunity cost associated with non-use of the capital which the institution must hold in order to hedge against the risk predicted by VaR (Sarma et al.,2003; Pipień, 2006). In our research we assume $c=1$. The cumulated value of $f^{p o z}$ is expressed as follows (Pipień, 2006):

$$
F L^{p o z}=\sum_{t=T}^{T+T^{\prime}} f_{t}^{p o z}
$$

The function is called firm's loss (FL) and enables to compare the VaR forecasts generated by different models in scope of market risk hedging. The model that generates too conservative VaR predictions will - unlike to (44) be penalized by the (47) due to inefficient maintenance of excess capital in order to hedge against market risks.

\section{Empirical Study}

\subsection{Descriptive statistics}

We analysed close price $\left(P_{t}\right)$ from August $1^{\text {st }}, 2008$ to October $10^{\text {th }}$, 2014 in case of gold (1593 observation), and from May $10^{\text {th }}, 2008$ to October $10^{\text {th }}, 2014$ (1851 observation) for oil. As an implied volatility we used CBOE Gold Volatility Index and CBOE Crude Oil Volatility Index $\left(\sigma_{t}^{\text {Implied }}\right)$. The indices measure the market's expectation of volatility implicit in the prices of options. The indices are leading barometers of investor 
sentiment and market volatility relating to listed options on an instrument with different strike prices, at the money (ATM) and out of the money (OTM), which are then averaged to provide hypothetical price of ATM options with a maturity of one month (22 days business). Daily volatility is calculated using scaling rule: $\sigma_{252}^{\text {Implied }}=\sqrt{252} \sigma_{1}^{\text {Implied }}$.

Table 1. Descriptive statistics

\begin{tabular}{cccccccc}
\hline Instrument & Median & Mean & $\begin{array}{c}\text { Std } \\
\text { deviation }\end{array}$ & Minimum & Maximum & Skewness & Kurtosis \\
\hline Gold & 0.0005 & 0.0002 & 0.0127 & -0.0888 & 0.1044 & -0.2497 & 10.0226 \\
Oil & 0.0008 & 0.0002 & 0.0239 & -0.1274 & 0.1503 & 0.0379 & 9.0206 \\
\hline
\end{tabular}

Table 2. The Lomnicki-Jarque-Bera test results

\begin{tabular}{ccc}
\hline Instrument & Statistics & p-value \\
\hline Gold & 24.5934 & 0.2174 \\
Oil & 83.5494 & 0.0000 \\
\hline
\end{tabular}

Table 3. The Ljung-Box test results

\begin{tabular}{ccccccc}
\hline Lags & \multicolumn{2}{c}{10} & \multicolumn{2}{c}{15} & \multicolumn{2}{c}{20} \\
\hline Instrument & Statistics & $p$-value & Statistics & $p$-value & Statistics & $p$-value \\
\hline Gold & 13.7835 & 0.1831 & 22.9158 & 0.0859 & 24.5934 & 0.2174 \\
Oil & 46.6134 & 0.0000 & 74.5049 & 0.0000 & 83.5494 & 0.0000 \\
\hline
\end{tabular}

Table 4. The Engle test results

\begin{tabular}{ccccccc}
\hline Lags & \multicolumn{2}{c}{10} & \multicolumn{2}{c}{15} & \multicolumn{2}{c}{20} \\
\hline Instrument & Statistics & p-value & Statistics & $p$-value & Statistics & p-value \\
\hline Gold & 89.3389 & 0.0000 & 105.6773 & 0.0000 & 148.0272 & 0.0000 \\
Oil & 413.6957 & 0.0000 & 488.4326 & 0.0000 & 522.1252 & 0.0000 \\
\hline
\end{tabular}

Table 5. The McLeod-Li test results

\begin{tabular}{ccccccc}
\hline Lags & \multicolumn{2}{c}{10} & \multicolumn{2}{c}{15} & \multicolumn{2}{c}{20} \\
\hline Instrument & Statistics & p-value & Statistics & p-value & Statistics & p-value \\
\hline Gold & 150.8873 & 0.0000 & 207.7756 & 0.0000 & 303.2220 & 0.0000 \\
Oil & 1300.5209 & 0.0000 & 1908.8351 & 0.0000 & 2553.6536 & 0.0000 \\
\hline
\end{tabular}

The time series of the quotations, prices and rates of return were checked for the presence of the following features: fatter tails than in the normal distribution (identified on the basis of the quantile-quantile plots, histograms and the Lomnicki-Jarque-Bera test); stationarity; autocorrelation of the rates of returns (checked with the Ljung-Box test); skewness, kurtosis of rates of return. The rate of returns have high degrees of kurtosis, a negative skewness is evident in case of gold. The oil time series is characterised by positive skewness. The Lomnicki-Jarque-Bera test rejects normality at the 5\%-level 
in case of oil. The standard deviation of the rate of returns is the highest in the case of oil. The Q test Ljung-Box in case of oil indicates autocorrelation. The Engle and McLeod-Li test confirms the existence of a strong and permanent nonlinear dependence.

Table 6. Gold. Estimated parameters of CAViaR and CAViaR-PlugIn models

\begin{tabular}{|c|c|c|c|c|c|c|c|c|c|}
\hline \multirow{3}{*}{ Model } & \multirow{3}{*}{ Parametr } & \multicolumn{4}{|c|}{ CAViaR } & \multicolumn{4}{|c|}{ Plugln } \\
\hline & & \multicolumn{2}{|c|}{ Long position } & \multicolumn{2}{|c|}{ Short position } & \multicolumn{2}{|c|}{ Long position } & \multicolumn{2}{|c|}{ Short position } \\
\hline & & 0.01 & 0.05 & 0.01 & 0.05 & 0.01 & 0.05 & 0.01 & 0.05 \\
\hline \multirow{5}{*}{ SAV } & $\beta_{1}$ & $\begin{array}{l}0.00041 \\
(0.0004)\end{array}$ & $\begin{array}{l}0.00008 \\
(0.0002)\end{array}$ & $\begin{array}{l}0.00037 \\
(0.0004)\end{array}$ & $\begin{array}{l}\mathbf{0 . 0 0 0 2 5} \\
(0.0002)\end{array}$ & $\begin{array}{c}-0.00223 \\
(0.0073)\end{array}$ & $\begin{array}{c}-0.00414 \\
(0.0050)\end{array}$ & $\begin{array}{c}-0.00156 \\
(0.0043)\end{array}$ & $\begin{array}{c}-0.00271 \\
(0.0027)\end{array}$ \\
\hline & $\beta_{2}$ & $\begin{array}{l}0.93857 \\
(0.0222)\end{array}$ & $\begin{array}{l}0.94362 \\
(0.0244)\end{array}$ & $\begin{array}{l}0.95419 \\
(0.0277)\end{array}$ & $\begin{array}{l}0.94818 \\
(0.0163)\end{array}$ & $\begin{array}{r}-0.35921 \\
(0.5209)\end{array}$ & $\begin{array}{c}-0.28538 \\
(1.1716)\end{array}$ & $\begin{array}{l}0.53545 \\
(0.4215)\end{array}$ & $\begin{array}{l}0.33501 \\
(0.4223)\end{array}$ \\
\hline & & 0.18587 & 0.11934 & 0.10555 & 0.07401 & 0.24365 & 0.08086 & -0.27554 & -0.14731 \\
\hline & $\beta_{3}$ & $(0.0698)$ & $(0.0537)$ & $(0.0612)$ & $(0.0189)$ & $(0.2447)$ & $(0.1983)$ & $(0.1014)$ & $(0.0757)$ \\
\hline & $\beta_{I Q}$ & & & & & $\begin{array}{l}1.47378 \\
(0.6732)\end{array}$ & $\begin{array}{l}1.55136 \\
(1.4107)\end{array}$ & $\begin{array}{l}0.64168 \\
(0.3212)\end{array}$ & $\begin{array}{l}0.95140 \\
(0.5991)\end{array}$ \\
\hline \multirow{6}{*}{ AS } & $\beta_{1}$ & $\begin{array}{l}0.00068 \\
(0.0007)\end{array}$ & $\begin{array}{l}0.00005 \\
(0.0002)\end{array}$ & $\begin{array}{l}0.00032 \\
(0.0003)\end{array}$ & $\begin{array}{l}0.00024 \\
(0.0002)\end{array}$ & $\begin{array}{c}-0.00194 \\
(0.0063)\end{array}$ & $\begin{array}{c}-0.00365 \\
(0.0021)\end{array}$ & $\begin{array}{c}-0.00995 \\
(0.0099)\end{array}$ & $\begin{array}{c}-0.00163 \\
(0.0021)\end{array}$ \\
\hline & $\beta_{2}$ & $\begin{array}{l}0.94322 \\
(0.0373)\end{array}$ & $\begin{array}{l}0.94893 \\
(0.0216)\end{array}$ & $\begin{array}{l}0.96706 \\
(0.0141)\end{array}$ & $\begin{array}{l}0.94679 \\
(0.0179)\end{array}$ & $\begin{array}{c}-0.14498 \\
(0.6099)\end{array}$ & $\begin{array}{l}0.34562 \\
(0.2039)\end{array}$ & $\begin{array}{l}0.07883 \\
(0.3584)\end{array}$ & $\begin{array}{l}0.40237 \\
(0.2845)\end{array}$ \\
\hline & $\beta_{3}$ & $\begin{array}{l}0.25113 \\
(0.1068)\end{array}$ & $\begin{array}{l}0.13757 \\
(0.0492)\end{array}$ & $\begin{array}{l}0.10653 \\
(0.0474)\end{array}$ & $\begin{array}{l}0.07312 \\
(0.0333)\end{array}$ & $\begin{array}{c}-0.32960 \\
(0.3141)\end{array}$ & $\begin{array}{c}-0.24975 \\
(0.1194)\end{array}$ & $\begin{array}{c}-0.21780 \\
(0.1142)\end{array}$ & $\begin{array}{r}-0.10120 \\
(0.0753)\end{array}$ \\
\hline & $\beta$ & -0.03450 & -0.08393 & -0.02525 & -0.08316 & -0.23637 & -0.15212 & 0.55140 & 0.22534 \\
\hline & $\rho_{4}$ & $(0.0785)$ & $(0.0491)$ & $(0.0316)$ & $(0.0208)$ & $(0.3469)$ & $(0.1318)$ & $(0.3182)$ & (0.1333) \\
\hline & $\beta_{I Q}$ & & & & & $\begin{array}{l}1.25475 \\
(0.6264)\end{array}$ & $\begin{array}{l}0.87372 \\
(0.3152)\end{array}$ & $\begin{array}{l}1.52731 \\
(0.8703)\end{array}$ & $\begin{array}{l}0.80735 \\
(0.3249)\end{array}$ \\
\hline \multirow{5}{*}{$\begin{array}{l}\text { Indirect } \\
\text { GARCH }\end{array}$} & $\beta_{1}$ & $\begin{array}{l}0.00002 \\
(0.0004)\end{array}$ & $\begin{array}{l}0.00000 \\
(0.0002)\end{array}$ & $\begin{array}{l}0.00001 \\
(0.0004)\end{array}$ & $\begin{array}{l}0.00000 \\
(0.0001)\end{array}$ & $\begin{array}{l}0.00004 \\
(0.0036)\end{array}$ & $\begin{array}{l}0.00015 \\
(0.0011)\end{array}$ & $\begin{array}{l}0.00023 \\
(0.0006)\end{array}$ & $\begin{array}{l}0.00003 \\
(0.0002)\end{array}$ \\
\hline & $\beta_{2}$ & $\begin{array}{l}0.91453 \\
(0.4147)\end{array}$ & $\begin{array}{l}0.95049 \\
(0.4265)\end{array}$ & $\begin{array}{l}0.95819 \\
(0.7352)\end{array}$ & $\begin{array}{l}0.95292 \\
(0.3599)\end{array}$ & $\begin{array}{l}0.32477 \\
(4.6846)\end{array}$ & $\begin{array}{l}0.37988 \\
(2.7296)\end{array}$ & $\begin{array}{l}\mathbf{0 . 0 3 2 8 1} \\
(0.6178)\end{array}$ & $\begin{array}{l}0.40679 \\
(0.8225)\end{array}$ \\
\hline & & 0.47486 & 0.15482 & 0.16744 & 0.07178 & 0.71078 & 0.03784 & 0.22551 & 0.04628 \\
\hline & $\beta_{3}$ & $(0.5825)$ & $(0.6343)$ & $(1.0813)$ & $(0.1408)$ & (7.8410) & & $(3.0804)$ & \\
\hline & $\beta_{I Q}$ & & & & & $\begin{array}{l}1.50097 \\
(9.4800)\end{array}$ & $\begin{array}{l}1.98863 \\
(6.6522)\end{array}$ & $\begin{array}{l}1.59270 \\
(1.6841)\end{array}$ & $\begin{array}{l}0.79010 \\
(0.9189)\end{array}$ \\
\hline \multirow{6}{*}{$A D$} & & -0.00003 & -0.00001 & -0.00001 & -0.00001 & -0.05703 & -0.04389 & 0.05029 & 0.00480 \\
\hline & & $(0.0000)$ & $(0.0000)$ & $(0.0000)$ & $(0.0000)$ & $(0.0546)$ & $(0.1450)$ & $(0.0470)$ & $(0.0470)$ \\
\hline & & & & & & 0.01650 & 0.56209 & -0.34653 & 0.42903 \\
\hline & & & & & & $(0.2477)$ & (1.0987) & $(0.3483)$ & $(0.9800)$ \\
\hline & $\beta_{3}$ & & & & & $\begin{array}{l}0.11134 \\
(0.0232)\end{array}$ & $\begin{array}{l}0.08988 \\
(0.0000)\end{array}$ & $\begin{array}{c}-0.12186 \\
(0.0018)\end{array}$ & $\begin{array}{c}-0.01272 \\
(0.0000)\end{array}$ \\
\hline & $\beta_{I Q}$ & & & & & $\begin{array}{l}1.36557 \\
(0.0546)\end{array}$ & $\begin{array}{l}0.84537 \\
(0.1540)\end{array}$ & $\begin{array}{l}1.53685 \\
(0.0677)\end{array}$ & $\begin{array}{l}0.61808 \\
(0.1400)\end{array}$ \\
\hline
\end{tabular}

Note: $0.01 ; 0.05-\alpha$-significance level of VaR; standard errors in bracktes; bolded values indicate significant parameters according to $t$ statistics. 


\subsection{Empirical research}

We perform estimation of CAViaR models (equations (3)-(9)), implied quantile model (equations (12)-(13)), encompassing method (equations (14)-(21)) and combining method of forecast (equations (22)-(27)). We use 1093 periods for gold and 1350 periods for oil to estimate parameters (insample) and 500 periods for post-sample evaluation of day-ahead quantile estimates using rolling window. For both instruments we indicate rate of returns $r_{t}$ and and an average returns in the sample $(\mu)$. We perform estimation for residuals $y_{t}=r_{t}-\mu$.

We estimate the parameters using, as Engle and Manganelli (2004), Doman, Doman (2009), Jeon and Taylor (2013), the Differential Evolution algorithm in $\mathrm{C}++$ and Matlab. The algorithm was presented by Price and Storn (1997).

Parameters of estimated models are contained in tables (6) and (7). For gold in the SAV models for long and short positions at the 0.05 level of probability and in the case of the model Indirect GARCH both long and short positions explanatory variable as empirical quantile turns out to be significant. For oil we observe a different situation. Only in the case of models SAV and the AS for a short position at the 0.05 significance level and for the $\mathrm{AD}$ model for long and short positions at the 0.01 significance level attached explanatory variable of empirical quantile turned out to be irrelevant.

To optimize the parameters of regression methods and the variancecovariance method we expressed the quantile regression minimization as a linear programme and applied the Nelder-Mead Simplex algorithm. The estimated parameter for the combined forecasts are contained in the Table (8).

In case of gold the forecast based on implied volatility receives a higher weight than the predictions from the CAViaR models. In case of the oil the implied quantile receives significantly higher weight when forecast is combined on the basis of CAViaR-AD model and implied quantile for long and short positions at the 0.01 significance level, and for a long position at the 0.05 significance level. But for a short position at the 0.05 significance level the implied quantile receives a significantly higher weight in the combination of implied quantile with the forecast based on SAV or Indirect GARCH model. 
Table 7. Oil. Estimated parameters of CAViaR and CAViaR-PlugIn models

\begin{tabular}{|c|c|c|c|c|c|c|c|c|c|}
\hline \multirow{3}{*}{ Model } & \multirow{3}{*}{ Parametr } & \multicolumn{4}{|c|}{ CAViaR } & \multicolumn{4}{|c|}{ Plugln } \\
\hline & & \multicolumn{2}{|c|}{ Long position } & \multicolumn{2}{|c|}{ Short position } & \multicolumn{2}{|c|}{ Long position } & \multicolumn{2}{|c|}{ Short position } \\
\hline & & 0.01 & 0.05 & 0.01 & 0.05 & 0.01 & 0.05 & 0.01 & 0.05 \\
\hline \multirow{4}{*}{ *SAV } & $\beta_{1}$ & $\begin{array}{l}0.00251 \\
(0.0007)\end{array}$ & $\begin{array}{l}0.00011 \\
(0.0002)\end{array}$ & $\begin{array}{l}0.00278 \\
(0.0015)\end{array}$ & $\begin{array}{l}0.00006 \\
(0.0002)\end{array}$ & $\begin{array}{c}-0.00062 \\
(0.0032)\end{array}$ & $\begin{array}{c}-0.00196 \\
(0.0029)\end{array}$ & $\begin{array}{c}-0.00074 \\
(0.0037)\end{array}$ & $\begin{array}{c}-0.00288 \\
(0.0013)\end{array}$ \\
\hline & $\beta_{2}$ & $\begin{array}{l}0.87120 \\
(0.0211)\end{array}$ & $\begin{array}{l}0.91757 \\
(0.0370)\end{array}$ & $\begin{array}{l}0.76330 \\
(0.0683)\end{array}$ & $\begin{array}{l}0.90003 \\
(0.0265)\end{array}$ & $\begin{array}{l}0.68751 \\
(0.1239)\end{array}$ & $\begin{array}{l}0.78916 \\
(0.1580)\end{array}$ & $\begin{array}{l}0.49449 \\
(0.2313)\end{array}$ & $\begin{array}{l}0.79478 \\
(0.0520)\end{array}$ \\
\hline & $\beta_{3}$ & $\begin{array}{l}0.27242 \\
(0.0466) \\
\end{array}$ & $\begin{array}{l}0.17969 \\
(0.0882) \\
\end{array}$ & $\begin{array}{l}0.55563 \\
(0.2154) \\
\end{array}$ & $\begin{array}{l}0.20181 \\
(0.0561) \\
\end{array}$ & $\begin{array}{l}0.24017 \\
(0.0486) \\
\end{array}$ & $\begin{array}{l}\mathbf{0 . 1 4 2 0 8} \\
(0.1666) \\
\end{array}$ & $\begin{array}{l}0.51237 \\
(0.2829) \\
\end{array}$ & $\begin{array}{l}0.22536 \\
(0.0638) \\
\end{array}$ \\
\hline & $\beta_{I Q}$ & & & & & $\begin{array}{l}0.26605 \\
(0.1846)\end{array}$ & $\begin{array}{l}\mathbf{0 . 2 0 5 2 4} \\
(0.1679)\end{array}$ & $\begin{array}{l}0.33959 \\
(0.2533)\end{array}$ & $\begin{array}{l}0.18180 \\
(0.0843)\end{array}$ \\
\hline \multirow{5}{*}{ AS } & $\beta_{1}$ & $\begin{array}{l}0.00303 \\
(0.0008)\end{array}$ & $\begin{array}{l}0.00010 \\
(0.0002)\end{array}$ & $\begin{array}{l}0.00218 \\
(0.0008)\end{array}$ & $\begin{array}{l}0.00048 \\
(0.0002)\end{array}$ & $\begin{array}{c}-0.00396 \\
(0.0084)\end{array}$ & $\begin{array}{c}-0.00053 \\
(0.0011)\end{array}$ & $\begin{array}{l}0.00225 \\
(0.0013)\end{array}$ & $\begin{array}{r}-0.00089 \\
(0.0009)\end{array}$ \\
\hline & $\beta_{2}$ & $\begin{array}{l}0.84521 \\
(0.0358)\end{array}$ & $\begin{array}{l}0.93895 \\
(0.0301)\end{array}$ & $\begin{array}{l}0.86735 \\
(0.0375)\end{array}$ & $\begin{array}{l}0.91141 \\
(0.0279)\end{array}$ & $\begin{array}{l}0.60910 \\
(0.2047)\end{array}$ & $\begin{array}{l}0.91166 \\
(0.0795)\end{array}$ & $\begin{array}{l}0.86953 \\
(0.0387)\end{array}$ & $\begin{array}{l}0.85358 \\
(0.0638)\end{array}$ \\
\hline & $\beta_{3}$ & $\begin{array}{l}0.25223 \\
(0.0585)\end{array}$ & $\begin{array}{l}0.09902 \\
(0.0823\end{array}$ & $\begin{array}{l}0.48895 \\
(0.1723)\end{array}$ & $\begin{array}{l}0.24716 \\
(0.0589)\end{array}$ & $\begin{array}{l}0.22894 \\
(0.0530)\end{array}$ & $\begin{array}{l}0.07790 \\
(0.1848)\end{array}$ & $\begin{array}{l}0.48150 \\
(0.1674)\end{array}$ & $\begin{array}{l}0.26358 \\
(0.1156)\end{array}$ \\
\hline & $\beta_{4}$ & $\begin{array}{r}-0.44066 \\
(0.1968) \\
\end{array}$ & $\begin{array}{c}-0.16163 \\
(0.0653)\end{array}$ & $\begin{array}{r}-0.01570 \\
(0.0790) \\
\end{array}$ & $\begin{array}{c}-0.06286 \\
(0.0564)\end{array}$ & $\begin{array}{c}-0.38298 \\
(0.2921)\end{array}$ & $\begin{array}{r}-0.16073 \\
(0.0923)\end{array}$ & $\begin{array}{c}-0.02043 \\
(0.0785)\end{array}$ & $\begin{array}{r}-0.05617 \\
(0.0831) \\
\end{array}$ \\
\hline & $\beta_{I Q}$ & & & & & $\begin{array}{l}0.40265 \\
(0.3612) \\
\end{array}$ & $\begin{array}{l}\mathbf{0 . 0 5 0 8 7} \\
(0.1275)\end{array}$ & $\begin{array}{c}-0.00280 \\
(0.0396)\end{array}$ & $\begin{array}{l}0.09615 \\
(0.0533) \\
\end{array}$ \\
\hline \multirow{4}{*}{$\begin{array}{l}\text { Indirect } \\
\text { GARCH }\end{array}$} & $\beta_{1}$ & $\begin{array}{l}0.00009 \\
(0.0008)\end{array}$ & $\begin{array}{l}0.00002 \\
(0.0004)\end{array}$ & $\begin{array}{l}0.00027 \\
(0.0005)\end{array}$ & $\begin{array}{l}0.00001 \\
(0.0003)\end{array}$ & $\begin{array}{l}0.00010 \\
(0.0007)\end{array}$ & $\begin{array}{l}0.00001 \\
(0.0008)\end{array}$ & $\begin{array}{l}0.00020 \\
(0.0009)\end{array}$ & $\begin{array}{l}0.00014 \\
(0.0010)\end{array}$ \\
\hline & $\beta_{2}$ & $\begin{array}{l}0.92011 \\
(0.2345)\end{array}$ & $\begin{array}{l}0.89439 \\
(0.4421)\end{array}$ & $\begin{array}{l}0.57487 \\
(0.1830) \\
\end{array}$ & $\begin{array}{l}0.88718 \\
(0.3737)\end{array}$ & $\begin{array}{l}0.76380 \\
(0.5136)\end{array}$ & $\begin{array}{l}0.85947 \\
(0.5754)\end{array}$ & $\begin{array}{l}\mathbf{0 . 3 3 3 6 9} \\
(1.6465)\end{array}$ & $\begin{array}{l}0.69506 \\
(0.9587) \\
\end{array}$ \\
\hline & $\beta_{3}$ & $\begin{array}{l}0.33190 \\
(0.0955)\end{array}$ & $\begin{array}{l}0.30253 \\
(0.2939)\end{array}$ & $\begin{array}{l}2.23002 \\
(1.6959)\end{array}$ & $\begin{array}{l}0.26633 \\
(0.2245)\end{array}$ & $\begin{array}{l}0.36438 \\
(0.0785)\end{array}$ & $\begin{array}{l}0.30606 \\
(0.5608)\end{array}$ & $\begin{array}{l}2.15737 \\
(1.8255)\end{array}$ & $\begin{array}{l}\mathbf{0 . 2 7 5 9 3} \\
(0.5857)\end{array}$ \\
\hline & $\beta_{I Q}$ & & & & & $\begin{array}{l}0.16353 \\
(0.4457)\end{array}$ & $\begin{array}{l}\mathbf{0 . 0 5 5 5 5} \\
(0.4795)\end{array}$ & $\begin{array}{l}0.41244 \\
(1.6413)\end{array}$ & $\begin{array}{l}\mathbf{0 . 3 3 3 1 3} \\
(1.0470)\end{array}$ \\
\hline \multirow{4}{*}{$A D$} & $\beta_{1}$ & $\begin{array}{r}-0.00006 \\
(0.0000)\end{array}$ & $\begin{array}{r}-0.00001 \\
(0.0000)\end{array}$ & $\begin{array}{l}-0.00009 \\
(0.0000)\end{array}$ & $\begin{array}{r}-0.00001 \\
(0.0000)\end{array}$ & $\begin{array}{r}-0.01450 \\
(0.0327)\end{array}$ & $\begin{array}{r}-0.01260 \\
(0.0000)\end{array}$ & $\begin{array}{c}-0.00243 \\
(0.0587)\end{array}$ & $\begin{array}{l}0.01063 \\
(0.0000)\end{array}$ \\
\hline & $\beta_{2}$ & & & & & $\begin{array}{l}0.46859 \\
(0.1660)\end{array}$ & $\begin{array}{l}0.87643 \\
(0.0000)\end{array}$ & $\begin{array}{l}\mathbf{0 . 1 3 1 4 6} \\
(0.2360)\end{array}$ & $\begin{array}{l}0.79313 \\
(0.0000)\end{array}$ \\
\hline & $\beta_{3}$ & & & & & $\begin{array}{l}0.01776 \\
(0.0000)\end{array}$ & $\begin{array}{l}\mathbf{0 . 0 2 3 5 9} \\
(0.0000)\end{array}$ & $\begin{array}{r}-0.01067 \\
(0.0000)\end{array}$ & $\begin{array}{r}-0.02933 \\
(0.0000)\end{array}$ \\
\hline & $\beta_{I Q}$ & & & & & $\begin{array}{l}0.72811 \\
(0.0636)\end{array}$ & $\begin{array}{l}\mathbf{0 . 2 4 5 1 2} \\
(0.0000)\end{array}$ & $\begin{array}{l}0.99871 \\
(0.0955)\end{array}$ & $\begin{array}{l}0.20844 \\
(0.0000)\end{array}$ \\
\hline
\end{tabular}

Note: $0.01 ; 0.05$ - $\alpha$-significance level of VaR; standard errors in bracktes; bolded values indicate significant parameters according to $t$ statistics.

Weights received on the basis of Weighted Averaged Combining method are included in a table (9). For gold, we observe that the forecast based on implied volatility receives a higher weight than the forecast from CAViaR models, and in the case of oil implied quantile receives a higher weight only in combining forecast of the implied quantile and CAViaR-AD. 
Table 8. Estimated parameters of linear combination method

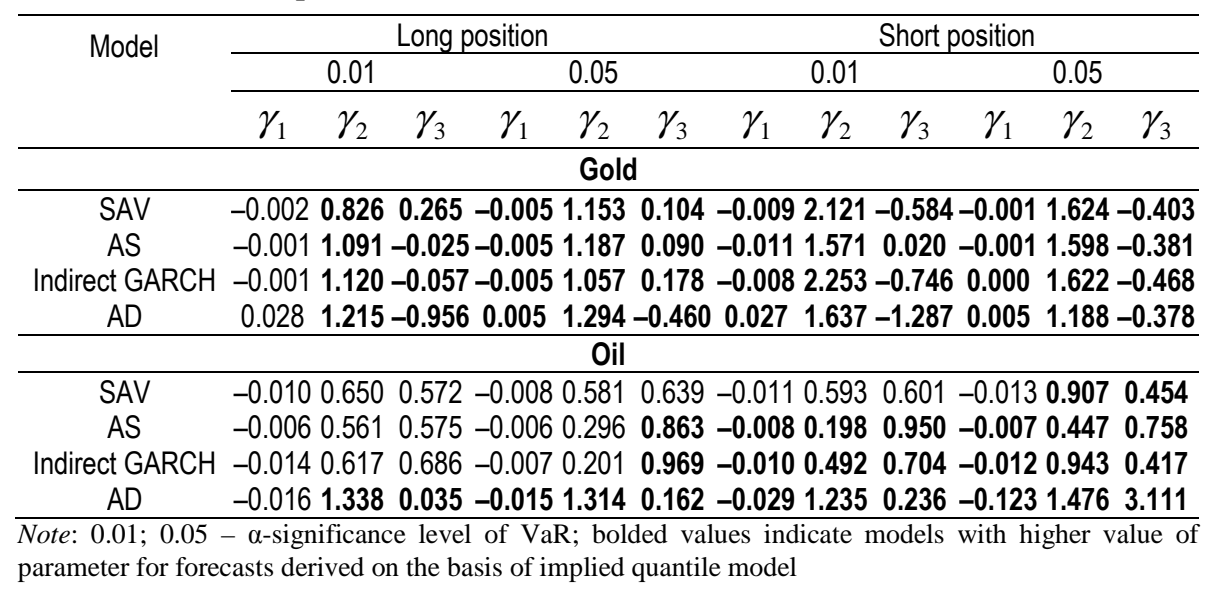

For determining the coefficient $\lambda$ the EWQR method is applied. EWQR estimation was carried out on the in-sample data with the last 500 observations excluded and considering a grid values for $\lambda$ between 0.97 and 1 with a step size of 0.001 . The smallest value of the function (28)-(29) was the criterion to determine the optimum values for $\lambda$ for the analysed significance levels of $\operatorname{VaR}(\alpha)$. The discount factor $\lambda$ for long and short positions and considered significance levels are shown in the table (10). The lower values for long positions mean that the 0.01 and the 0.05 quantile change more dynamically over time than the 0.01 and the 0.05 quantile in the case of a short position.

Table 9. Estimated weights of Weighted Averaged Combining method

\begin{tabular}{|c|c|c|c|c|c|}
\hline \multirow[t]{2}{*}{ Instrument } & \multirow[t]{2}{*}{ Model } & \multicolumn{2}{|c|}{ Long position } & \multicolumn{2}{|c|}{ Short position } \\
\hline & & 0.01 & 0.05 & 0.01 & 0.05 \\
\hline \multirow{4}{*}{ Gold } & SAV & 0.5996 & 0.7290 & 0.8339 & 0.9066 \\
\hline & AS & 0.7771 & 0.6058 & 0.7016 & 0.9067 \\
\hline & Indirect GARCH & 0.5198 & 0.7028 & 0.7731 & 0.9281 \\
\hline & $A D$ & 0.9519 & 0.9696 & 0.9760 & 0.9762 \\
\hline \multirow{4}{*}{ Oil } & SAV & 0.3193 & 0.3928 & 0.4083 & 0.2192 \\
\hline & AS & 0.0822 & 0.2564 & 0.0439 & 0.0966 \\
\hline & Indirect GARCH & 0.3288 & 0.0832 & 0.3052 & 0.2480 \\
\hline & $A D$ & 0.9770 & 0.9280 & 0.9071 & 0.9295 \\
\hline
\end{tabular}

Note: $0.01 ; 0.05-\alpha$-significance level of $\mathrm{VaR}$; bolded values indicate models with higher weight $\omega$ assigned to forecasts from implied quantile model 
Table 10. Estimated Exponential Weight $\lambda$

\begin{tabular}{cccccc}
\hline Instrument & Model & \multicolumn{2}{c}{ Long position } & \multicolumn{2}{c}{ Short position } \\
\cline { 3 - 6 } a-significance level of VaR & 0.01 & 0.05 & 0.01 & 0.05 \\
\hline \multirow{3}{*}{ Gold } & SAV & 0.996 & 0.996 & 1.000 & 1.000 \\
& AS & 1.000 & 0.982 & 1.000 & 1.000 \\
& Indirect GARCH & 1.000 & 0.991 & 0.993 & 1.000 \\
& AD & 0.991 & 1.000 & 1.000 & 0.995 \\
\hline \multirow{2}{*}{ Oil } & SAV & 0.970 & 0.998 & 1.000 & 0.999 \\
& AS & 1.000 & 0.998 & 1.000 & 1.000 \\
& Indirect GARCH & 1.000 & 0.998 & 1.000 & 0.998 \\
& AD & 0.993 & 0.981 & 0.997 & 1.000 \\
\hline
\end{tabular}

The estimated values of weights for Weighted Averaged Combining Optimized using Exponential Weighting is included in the table (11). We see the opposite situation than in the case of Weighted Averaged Combining without discounting factor. In the considered combinations, the forecasts from the CAViaR models receive a significantly higher weight (>0.93).

Table 11. Estimated weights of Weighted Averaged Combining Optimized using Exponential Weighting

\begin{tabular}{cccccc}
\hline \multicolumn{2}{c}{ Instrument } & Model & \multicolumn{2}{c}{ Long position } & \multicolumn{2}{c}{ Short position } \\
\hline \multicolumn{2}{c}{ a-significance level of VaR } & 0.01 & 0.05 & 0.01 & 0.05 \\
\multirow{4}{*}{ Gold } & SAV & 0.008 & 0.026 & 0.009 & 0.036 \\
& AS & 0.007 & 0.028 & 0.009 & 0.036 \\
& Indirect GARCH & 0.008 & 0.028 & 0.009 & 0.037 \\
& AD & 0.007 & 0.023 & 0.009 & 0.036 \\
\hline \multirow{2}{*}{ Oil } & SAV & 0.016 & 0.060 & 0.019 & 0.062 \\
& AS & 0.016 & 0.058 & 0.016 & 0.058 \\
& Indirect GARCH & 0.015 & 0.063 & 0.018 & 0.063 \\
& AD & 0.015 & 0.062 & 0.025 & 0.066 \\
\hline
\end{tabular}

Results of measures are presented in tables (12) for gold and (13) for oil.

\section{Conclusions}

In the present study the CAViaR models, the encompassing method and the combined forecasts methods are applied to determine the risk measure $\mathrm{VaR}$. Since none of the forecasts is dominant and there is no universally accepted ranking of the various methods, we decided to check if the encompassing method or the forecast combination methods may reduce the risk of a large forecast error compared to individual forecast. 
Table 12. Gold. Loss functions for post sample

\begin{tabular}{|c|c|c|c|c|c|c|c|c|c|c|c|c|c|}
\hline \multirow{2}{*}{\multicolumn{2}{|c|}{ Model/metoda }} & \multicolumn{4}{|c|}{$\mathrm{BL}$} & \multicolumn{4}{|c|}{$\mathrm{FL}$} & \multicolumn{4}{|c|}{$\mathrm{RL}$} \\
\hline & & \multicolumn{2}{|c|}{$\begin{array}{c}\text { long } \\
\text { position }\end{array}$} & \multicolumn{2}{|c|}{$\begin{array}{c}\text { short } \\
\text { position }\end{array}$} & \multicolumn{2}{|c|}{$\begin{array}{l}\text { long } \\
\text { position }\end{array}$} & \multicolumn{2}{|c|}{$\begin{array}{l}\text { short } \\
\text { position }\end{array}$} & \multicolumn{2}{|c|}{$\begin{array}{c}\text { long } \\
\text { position }\end{array}$} & \multicolumn{2}{|c|}{$\begin{array}{l}\text { short } \\
\text { position }\end{array}$} \\
\hline & $a$ & 0.01 & 0.05 & 0.01 & 0.05 & 0.01 & 0.05 & 0.01 & 0.05 & 0.01 & 0.05 & 0.01 & 0.05 \\
\hline & $\mathrm{IQ}$ & 15 & 40 & 8 & 32 & 87.22 & 153.25 & 23.33 & 56.22 & 76.02 & 146.41 & 13.73 & 50.34 \\
\hline \multirow{6}{*}{ SAV } & CAViaR & 7 & 35 & 2 & 16 & 63.80 & 133.08 & 17.27 & 35.02 & 49.26 & 124.91 & 4.60 & 27.46 \\
\hline & Plug & 13 & 40 & 10 & $\overline{35}$ & 66.86 & & 25.66 & 58.53 & 54.80 & 137.31 & 16.25 & 52.83 \\
\hline & LinearC & 10 & 43 & 12 & 29 & 75.95 & 160.81 & 28.79 & 52.09 & 63.61 & 154.35 & 20.01 & 46.00 \\
\hline & & 10 & 35 & 3 & 20 & 73.65 & 139.98 & 17.96 & 41.08 & 60.78 & 132.44 & 6.79 & 34.31 \\
\hline & & 10 & 38 & 5 & 32 & 75.23 & & 20.08 & 56.27 & 62.67 & 139.32 & 9.93 & 50.40 \\
\hline & WtdA & 7 & 35 & 2 & 16 & 63.90 & 133.41 & 17.26 & 35.14 & 49.39 & 125.27 & 4.62 & 27.63 \\
\hline \multirow{6}{*}{ AS } & & 8 & 35 & 2 & 16 & 79.72 & 142.30 & 17.04 & 35.28 & 65.61 & 134.49 & 4.03 & 27.79 \\
\hline & Plugln & 15 & 52 & 10 & 31 & 69.21 & 32 & 25.85 & 54.38 & 57.75 & 152.94 & 16.70 & 48.60 \\
\hline & LinearComb & 14 & 45 & 6 & 29 & 83.31 & 163.03 & 21.51 & 51.85 & 71.70 & 156.58 & 11.41 & 45.72 \\
\hline & Simp & 11 & 38 & 3 & 20 & 82.60 & 147.74 & 17.77 & 41.23 & 69.94 & 140.42 & 6.43 & 34.50 \\
\hline & & 12 & 38 & 4 & 32 & & & 18.84 & 56.27 & 71.96 & 141.16 & 8.17 & 50.40 \\
\hline & WtdAvg & 8 & 35 & 2 & 16 & 79.72 & 142.41 & 17.04 & 35.40 & 65.62 & 134.63 & 4.05 & 27.95 \\
\hline \multirow{6}{*}{$\begin{array}{l}\text { Indirect } \\
\text { GARCH }\end{array}$} & CAVis & 9 & 31 & $\underline{2}$ & 14 & 56.45 & 118.36 & $\overline{17.44}$ & 32.92 & 41.77 & 109.45 & 4.74 & 25.15 \\
\hline & Plugln & 3 & 4 & $\underline{\overline{2}}$ & 12 & 36.75 & 61.98 & 17.73 & 29.92 & 18.47 & 46.66 & 2.80 & 21.95 \\
\hline & LinearComb & 15 & 41 & $\overline{\overline{14}}$ & 33 & 86.04 & 155.96 & 32.44 & 57.16 & 74.58 & 149.32 & 24.03 & 51.25 \\
\hline & Simp & 10 & 34 & 3 & 20 & 68.26 & 133.03 & 18.05 & 40.74 & 55.28 & 125.13 & 6.87 & 33.89 \\
\hline & & 11 & 36 & 5 & 32 & 69.72 & & 20.06 & 56.49 & 56.84 & 132.93 & 9.73 & 50.65 \\
\hline & WtdA & 9 & 31 & 2 & 15 & & & 17.43 & 34.02 & 41.96 & 110.10 & 4.76 & 26.31 \\
\hline \multirow{6}{*}{$A D$} & & 10 & 25 & 4 & 32 & & & 19.68 & 61.71 & 68.48 & 114.45 & 5.98 & \\
\hline & & 15 & $\overline{51}$ & 8 & 32 & 68.35 & 15 & 24.49 & 55.07 & 57.01 & 147.15 & 14.59 & 49.1 \\
\hline & LinearComb & 5 & 40 & 4 & 15 & 62.64 & 149.55 & 19.06 & 34.03 & 47.34 & 142.51 & 7.67 & 26.68 \\
\hline & & 12 & 28 & 4 & 30 & 83.04 & & 18.93 & 56.13 & 71.06 & 124.17 & 7.24 & 50.06 \\
\hline & & 14 & 42 & 7 & 32 & 86.03 & & 22.29 & 56.27 & 74.75 & 153.26 & 12.57 & 50.38 \\
\hline & WtdAvgExp & 10 & 26 & 4 & 32 & 81.22 & 124.64 & 19.66 & 61.38 & 68.48 & 115.70 & 6.00 & 55.16 \\
\hline
\end{tabular}

Note: 0.01 ; 0.05 - $\alpha$-significance level of VaR; bolded value indicates models/methods that both tests based on Bernoulli trials model and dynamic quantile test indicate as adequate, underlined value is the lowest value among the models/methods for the analysed position and the significance level.

The subject of the study were two assets: gold and oil. For crude oil, in the encompassing method we observe significant contribution of the implied volatility to the VaR. For gold, the implied quantile has been assigned a higher weight in the method of Linear Combination and Weighted Averaged Combining method.

Conclusions made by Jeon and Taylor (2013), who analyzed the CAViaR models, the encompassing method and the combination methods for the capital market indices differ from the one presented in this study for the commodities. Jeon and Taylor (2013) using backtests and the Dynamic Quantile test pointed out the forecast determined by combining methods as more adequate than coming from CAViaR models or the implied quantile model. In their view, the encompassing method derives more accurate 
forecasts than the individual CAViaR models or the implied quantile model individually, but considering only the criterion of the smallest fraction of exceedances Hit (Table (5) in Jeon and Taylor (2013)). Among the methods of combining forecasts Jeon and Taylor (2013) pointed out that the linear combination method and the arithmetic mean method generate the most adequate VaR.

Table 13. Oil. Loss functions for post sample

\begin{tabular}{|c|c|c|c|c|c|c|c|c|c|c|c|c|c|}
\hline \multirow{2}{*}{\multicolumn{2}{|c|}{ Method/model }} & \multicolumn{4}{|c|}{$\mathrm{BL}$} & \multicolumn{4}{|c|}{$\mathrm{FL}$} & \multicolumn{4}{|c|}{$\mathrm{RL}$} \\
\hline & & \multicolumn{2}{|c|}{$\begin{array}{c}\text { long } \\
\text { position }\end{array}$} & \multicolumn{2}{|c|}{$\begin{array}{c}\text { short } \\
\text { position }\end{array}$} & \multicolumn{2}{|c|}{$\begin{array}{c}\text { long } \\
\text { position }\end{array}$} & \multicolumn{2}{|c|}{$\begin{array}{l}\text { short } \\
\text { position }\end{array}$} & \multicolumn{2}{|c|}{$\begin{array}{c}\text { long } \\
\text { position }\end{array}$} & \multicolumn{2}{|c|}{$\begin{array}{c}\text { short } \\
\text { position }\end{array}$} \\
\hline & $a$ & 0.01 & 0.05 & 0.01 & 0.05 & 0.01 & 0.05 & 0.01 & 0.05 & 0.01 & 0.05 & 0.01 & 0.05 \\
\hline & $\mathrm{IQ}$ & 8 & 24 & 4 & 28 & 53.53 & 91.59 & 19.90 & 49.10 & 38.92 & 81.89 & 5.19 & 39.78 \\
\hline \multirow{6}{*}{ SAV } & CAViaR & 6 & 24 & $\underline{2}$ & 30 & 27.18 & 75.88 & 18.94 & 50.55 & 7.74 & 65.51 & 2.02 & 41.36 \\
\hline & Plugln & 9 & 51 & 10 & 65 & 44.49 & 132.40 & 25.07 & 112.84 & 29.46 & 124.69 & 11.22 & 106.70 \\
\hline & LinearComb & 8 & 42 & 10 & 59 & 40.44 & 115.63 & 24.97 & 105.85 & 24.87 & 107.44 & 11.76 & 99.59 \\
\hline & Simr & 7 & 25 & 0 & 27 & 35.47 & 81.99 & 15.88 & 46.29 & 18.46 & 72.00 & 0.00 & 37.01 \\
\hline & & 7 & 24 & 0 & 27 & 31.72 & 79.47 & 16.08 & 46.76 & 13.85 & 69.38 & 0.00 & 37.50 \\
\hline & Wtd $A$ & 6 & 23 & $\underline{2}$ & 29 & 27.27 & 75.25 & 18.90 & 49.29 & 7.91 & 64.92 & 2.02 & 40.08 \\
\hline \multirow{6}{*}{ AS } & & 5 & 23 & 1 & 20 & 26.86 & 77.04 & 18.58 & 35.75 & 6.62 & 66.64 & 1.10 & 25.07 \\
\hline & Plug & 11 & 38 & 1 & 34 & 55.47 & 108.30 & 18.73 & 60.07 & 41.76 & 99.63 & 1.07 & 51.86 \\
\hline & LinearC & 7 & 35 & 4 & 27 & 36.01 & 101.16 & 19.97 & 48.09 & 19.04 & 92.17 & 4.60 & 39.09 \\
\hline & & 6 & 25 & 0 & 25 & 34.13 & 83.56 & 16.15 & 41.35 & 16.70 & 73.55 & 0.00 & 31.40 \\
\hline & & 5 & 24 & 1 & 22 & 27.17 & 79.86 & 18.43 & 37.66 & 7.39 & 69.66 & 1.08 & 27.14 \\
\hline & WtdAvgExp & 5 & 23 & 1 & 21 & 26.90 & 77.38 & 18.52 & 36.69 & 6.75 & 67.01 & 1.09 & 26.10 \\
\hline \multirow{6}{*}{$\begin{array}{l}\text { Indirect } \\
\text { GARCH }\end{array}$} & $R$ & 3 & $\underline{18}$ & 0 & 23 & 25.45 & $\underline{58.71}$ & 18.65 & 39.65 & 4.52 & $\underline{47.11}$ & 0.00 & 29.57 \\
\hline & & 6 & 20 & 0 & 0 & 33.06 & $\overline{63.24}$ & 18.08 & 16.03 & 15.50 & $\overline{52.08}$ & 0.00 & 0.00 \\
\hline & Line & 6 & 26 & 5 & 53 & 37.19 & 78.81 & 20.19 & 92.12 & 20.71 & 68.92 & 5.10 & 85.37 \\
\hline & Sim & 6 & $\underline{18}$ & 0 & 25 & 34.84 & 69.12 & 16.72 & 42.12 & 17.11 & 58.41 & 0.00 & 32.44 \\
\hline & Wtd $A$ & 5 & $\underline{18}$ & 0 & 26 & 30.59 & 60.08 & 17.47 & 42.59 & 11.78 & 48.63 & 0.00 & 32.75 \\
\hline & WtdAvgExp & 3 & 19 & 0 & 24 & 25.52 & 60.71 & 18.58 & 40.57 & 4.68 & 49.24 & 0.00 & 30.57 \\
\hline \multirow{6}{*}{$A D$} & CAViaR & 0 & 5 & 0 & 5 & 29.80 & 34.08 & 19.28 & 20.99 & 0.00 & 16.00 & 0.00 & 5.50 \\
\hline & & 12 & 45 & 13 & 90 & 68.43 & 142.19 & 29.38 & 161.95 & 54.95 & 134.43 & 16.61 & 156.82 \\
\hline & LinearComb & 15 & 44 & 59 & 205 & 77.90 & 132.14 & 114.91 & 470.52 & 65.61 & 124.19 & 107.58 & 468.66 \\
\hline & & 0 & 8 & 0 & 11 & 34.45 & 49.03 & 18.96 & 25.55 & 0.00 & 35.05 & 0.00 & 13.10 \\
\hline & & 10 & 34 & 4 & 55 & 59.29 & 113.07 & 19.77 & 101.50 & 45.54 & 104.52 & 5.42 & 94.84 \\
\hline & WtdAvgExp & 0 & 5 & 0 & 5 & 30.73 & 35.10 & 19.21 & 20.69 & 0.00 & 17.51 & 0.00 & 5.57 \\
\hline
\end{tabular}

Note: $0.01 ; 0.05-\alpha$-significance level of VaR; bolded value indicates models/methods that both tests based on Bernoulli trials model and dynamic quantile test indicate as adequate, underlined value is the lowest value among the models/methods for the analysed position and at the significance level.

In our research, the Kupiec test is used in conjunction with the Dynamic Quantile test and the Christoffersen test, so the models and methods that underestimate or overestimate VaR are rejected. We show that the criteria based on the Kupiec, the Christoffersen and the Dynamic Quantile test 
together more precisely classify the VaR forecasting method than the one used by Jeon and Taylor (2013). Proposals of evaluation VaR models formulated in this study may protect the institution against errors arising from the application of methods pointed out by Jeon and Taylor (2013), and inefficiently maintaining too high level of capital.

In the case of the commodities neither the encompassing method nor the combining forecast method improve $\mathrm{VaR}$ forecasts. The method of choosing the most adequate model presented in this paper leads to the CAViaR-SAV model selection as the source of most optimal measure of risk forecasts. The Kupiec test, the Christoffersen and the Dynamic Quantile test indicate the model as an adequate to forecast VaR for gold and oil for short positions at the 0.01 and the 0.05 significance level, and for a long position at the 0.05 significance level. The model generates also the lowest value of loss functions.

In our study, none of the models and none of the methods have predicted adequately the VaR for a long position at the 0.01 significance level, leading to the conclusion that the choice of model should also depend on the financial institution's investment strategy and portfolio structure.

\section{References}

Armendola, A., Storti, G. (2008), A GMM procedure for combining volatility forecasts, Computational Statistics and Data Analysis, 52, 3047-3060.

Armstrong, J. S. (2001), Principles of Forecasting: A Handbook for Researchers and Practitioners, Dordrecht, Kluwer Academic Publishers, DOI: http://dx.doi.org/10.1007/978-0-306-47630-3.

Artzner, P., Delbaen, F., Ebe,r J.-M., Heath, D. (1999), Coherent Measures of Risk, Mathematical Finance, 9, 203-228.

Bates, J. M., Granger, C. W. J. (1969), The combination of forecasts, Operations Research Quarterly, 20, 451-468, DOI: http://dx.doi.org/10.2307/3008764.

Blair, B. J, Poon, S .H., Taylor, S. J. (2001), Forecasting S\&P 100 volatility: The incremental information content of implied volatilities and high-frequency index returns, Journal of Econometrics, 105, 5-26, DOI: http://dx.doi.org/10.1016/S0304-4076(01)00068-9.

Boudoukh, J., Richardson, M., Whitelaw, R. F. (1998), The best of both worlds, Risk, 11, 64-67.

Bunn, D. W. (1989), Forecasting with more than one model, Journal of Forecasting, 8, 161-166, DOI: http://dx.doi.org/10.1002/for.3980080302.

Chong, J. (2004), Value at risk from econometric models and implied from currency options, Journal of Forecasting, 23, 603-620, DOI: http://dx.doi.org/10.1002/for.934.

Chong, Y., Henry, D. F. (1986), Econometric evaluation of linear macro-economic models, Review of Economic Studies, 53, 671-690, DOI: http://dx.doi.org/10.2307/2297611.

Christoffersen, P. (1998), Evaluating interval forecasts, International Economics Review, 39, 841-862, DOI: http://dx.doi.org/10.2307/2527341. 
Christoffersen, P .F., Mazzotta, S. (2005), The accuracy of density forecasts from foreign exchange options, Journal of Financial Econometrics, 3, 578-605, DOI: http://dx.doi.org/10.1093/jjfinec/nbi021.

Claessen, H, Mittnik, S. (2002), Forecasting stock market volatility and the informational efficiency of the DAX-index options market, The European Journal of Finance, 8, 302-321, DOI: http://dx.doi.org/10.1080/13518470110074828.

Clemen, R. T. (1986), Linear constraints and the efficiency of combined forecasts, Journal of Forecasting, 5, 31-38, DOI: http://dx.doi.org/10.1002/for.3980050104.

Corredor, P., Santamaria, R. (2004), Forecasting volatility in the Spanish option market, Applied Financial Econometrics, 14, 1-11,

DOI: http://dx.doi.org/10.1080/0960310042000164176.

Crane, D. B., Crotty, J. R. (1967), A two-stage forecasting model: Exponential smoothing and multiple regression, Management Science, 13, 501-507, DOI: http://dx.doi.org/10.1016/B978-0-08-019605-3.50019-5.

Day, T. E., Lewis, C. M. (1992), Stock market volatility and the information content of stock index options, Journal of Econometrics, 52, 267-287, DOI: http://dx.doi.org/10.1016/0304-4076(92)90073-Z.

Diebold, F. X. (1988), Serial correlation and combination of forecasts, Journal of Business and Economic Statistics, 6, 105-111,

DOI: http://dx.doi.org/10.1080/07350015.1988.10509642.

Diebold, F. X. (1989), Forecast combination and ecompassing: Reconciling two divergent literatures, International Journal of Forecasting, 2, 589-592.

Doidge, C., Wei, J. Z. (1998), Volatility forecasting and the efficiency of the Toronto 35 index options market, Canadian Journal of Administrative Sciences, 15, 28-38, DOI: http://dx.doi.org/10.1111/j.1936-4490.1998.tb00150.x.

Doman, M., Doman, R. (2009), Volatility and risk modeling, Oficyna Wolters Kluwer Business, Kraków.

Donaldson, R. G., Kamstra, M. J. (2005), Volatility forecasts, trading volume, and the ARCH versus option-implied volatility trade-off, The Journal of Financial Research, 28, 519-538, DOI: http://dx.doi.org/10.1111/j.1475-6803.2005.00137.x.

Capital Requirements Directive IV, CRD IV, Dz. Urz. UE L176, June 27th, 2013.

Engle, R. F., Manganelli, S. (2004), CAViaR: conditional autoregressive Value at Risk by regression quantiles, Journal of Business and Economic Statistics, 22, 367-381, DOI: http://dx.doi.org/10.1198/073500104000000370.

Fiszeder, P. (2009), GARCH class models in empirical financial research, Wydawnictwo Naukowe UMK, Toruń.

Giacomini, R., Komunjer, I. (2005), Evaluation and combination of conditional quantile forecasts, Journal of Business and Economic Statistics, 23, 416-431, DOI: http://dx.doi.org/10.1198/073500105000000018.

Giot, P. (2005), Implied volatility indexes and daily value at risk models, Journal of Derivatives, 12, 54-64, DOI: http://dx.doi.org/10.3905/jod.2005.517186.

Giot, P., Laurent, S. (2007), The information content of implied volatility in light of the jump/continuous decomposition of realized volatility, Journal of Futures Markets, 27, 337-359, DOI: http://dx.doi.org/10.1002/fut.20251.

Grajek, M. (2002), Prognozy łączone (Combining Forecasts), Przeglad Statystyczny, 2, $70-81$.

Granger, C. W. J. (1989), Invited review: Combining forecasts-20 years later, Journal of Forecasting, 8, 167-173.

Dynamic Econometric Models 15 (2015) 129-156 
Granger, C. W. J., White, H., Kamstra, M. J. (1989), Interval forecasting: An analysis based upon ARCH-quantile estimators, Journal of Econometrics, 40, 87-96, DOI: http://dx.doi.org/10.1016/0304-4076(89)90031-6.

Greszta, M., Maciejewski, W. (2005), Kombinowanie prognoz gospodarki Polski (Combining Forecasts of the Polish Economy), Gospodarka Narodowa, 5-6, 49-60.

Iwanicz-Drozdowska, M. (2005), Zarzadzanie Finansowe Bankiem (Financial Management of Bank), Warsaw, PWE.

Jajuga, K., Jajuga, T. (2011), Instrumenty finansowe, aktywa niefinansowe, ryzyko finansowe, inżynieria finansowa (Financial instruments, Non-financial Assets, Financial Risk, Financial Engineering), PWN, Warsaw.

Jarque, C. M., Bera, A. K. (1987), A Test for Normality of Observations and Regression Residuals, International Statistical Review, 55, 163-172.

DOI: http://dx.doi.org/10.2307/1403192.Jeon J., Taylor J.W (2013), Using CAViaR Models with Implied Volatility for Value at Risk Estimation, Journal of Forecasting, 32, 62-74, DOI: http://dx.doi.org/10.1002/for.1251.

Koenker, R., Bassett, G. S. (1978), Regression quantiles, Econometrica, 46, 33-50, DOI: http://dx.doi.org/10.2307/1913643.

Kupiec, P. (1995), Techniques for Verifying the Accuracy of Risk Measurement Models, Journal of Derivatives, 3, 73-84, DOI: http://dx.doi.org/10.3905/jod.1995.407942.

Lomnicki, Z. A. (1961), Tests for Departure from Normality in the Case of Linear Stochastic Processes, Metrika, 4, 37-62, DOI: http://dx.doi.org/10.1007/BF02613866.

Lopez, J. A. (1998), Testing your Risk test, The Financial Survey, 18-20.

Lopez, J. A. (1999), Methods for Evaluating Value at Risk Estimates, FRBNY Economic Policy Review, 2, 3-15, DOI: http://dx.doi.org/10.2139/ssrn.1029673.

Mazur, B., Pipień, M. (2012), On the Empirical Importance of Periodicity in the Volatility of Financial Returns - Time Varying GARCH as a Second Order APC(2) Process, Central European Journal of Economic Modelling and Econometrics, 4, 95-116.

Mittnik, S., Paolella, M. S. (2000), Conditional density and value-at-risk prediction of Asian currency exchange rates, Journal of Forecasting, 19, 313-333, DOI: http://dx.doi.org/10.1002/1099-131X(200007)19:4\%3C313::AIDFOR776\%3E3.0.CO;2-E.

Nelson, C. R. (1972), The prediction performance of the F.R.B.-M.I.T.-PENN model of the U.S. economy, American Economic Review, 62, 902-917.

Nelson, C. R. (1984), A benchmark for the accuracy of econometric forecasts of GNP, Business Economics, 19, 52-58.

Noh, J., Kim, T. H. (2006), Forecasting volatility of futures market: The S\&P 500 and FTSE 100 futures using high frequency returns and implied volatility, Applied Economics, 38, 395-413, DOI: http://dx.doi.org/10.1080/00036840500391229.

Perignon, C., Smith, D. R. (2010), The Level and Quality of Value-at-Risk Disclosure by Commercial Banks, Journal of Banking and Finance, 34, 362-377, DOI: http://dx.doi.org/10.2139/ssrn.952595.

Piłatowska, M. (2009), Prognozy kombinowane z wykorzystaniem wag Akaike'a, w: Ekonomia XXXIX. Dynamiczne Modele Ekonometryczne, Wydawnictwo Naukowe Uniwersytetu Mikołaja Kopernika, Toruń, 51-62.

Piontek, K. (2000), Modelowanie finansowych szeregów czasowych warunkową wariancją, w: Prace Naukowe Akademii Ekonomicznej we Wroctawiu, 890, 218-226.

Pipień, M. (2006), Wnioskowanie Bayesowskie w Ekonometrii finansowej, w: Zeszyty Naukowe Akademia Ekonomiczna, 176, Kraków. 
Pong, S., Shackleton, M. B., Taylor, S. J., Xu, X. (2004), Forecasting currency volatility: A comparison of implied volatilities and AR (FI) MA models, Journal of Banking and Finance, 28, 2541-2563, DOI: http://dx.doi.org/10.2139/ssrn.301981.

Price, K., Storn, R. (1997), Differential Evolution, Dr. Dobb's Journal, 18-24, DOI: http://dx.doi.org/10.1007/978-3-642-30504-7_8.

Rachev, S., Mittnik, S. (2002), Stable Paretian Models in Finance, John Wiley, New York.

Ratuszny, E. (2013), Robust Estimation in VaR Modelling - Univariate Approaches using Bounded Innovation Propagation and Regression Quantiles Methodology, Central European Journal of Economic Modelling and Econometrics, 5, 35-63.

Ratuszny, E. (2015), Influence of robust estimation on Value at Risk. Bounded Innovation Propagation and regression quantiles method, Journal of Management and Financial Sciences, forthcoming.

Sarma, M., Thomas, S., Shah, A. (2003), Selecting of VaR Models, Journal of Forecasting, 22, 337-358.

Szakmary, A., Ors, E., Kim, J. K., Davidson III, W. N. (2003), The predictive power of implied volatility: Evidence from 35 futures markets, Journal of Banking and Finance, 27, 2151-2175, DOI: http://dx.doi.org/10.1016/S0378-4266(02)00323-0.

Taylor, J. W. (2008), Using exponentially weighted quantile regression to estimate value at risk and expected shortfall, Journal of Financial Econometrics, 6, 382-406, DOI: http://dx.doi.org/10.1093/jifinec/nbn007.

Taylor, J. (1999), A Quantile Regression Approach to Estimating the Distribution of Multiperiod Returns, Journal of Derivatives, 64-78, DOI: http://dx.doi.org/10.3905/jod.1999.319106.

Taylor, J. W., Bunn, D. W. (1998), Combining forecast quantiles using quantile regression: Investigating the derived weights, estimator bias and imposing constraints, Journal of Applied Statistics, 25, 193-206, DOI: http://dx.doi.org/10.1080/02664769823188.

Umantsev, L., Chernozhukov, V. (2001), Conditional Value at risk: Aspects of modeling and estimation, Empirical Economics, 26, 271-292.

Zarnowitz, V. (1967), An appraisal of short-term economic forecasts, National Bureau of Economic Research, New York. 